\title{
Methicillin-Resistant Staphylococcus aureus [MRSA] Infections in the Department of Defense [DOD]: Annual Summary 2013
}

\section{NMCPHC-EDC-TR-44-2015}

\section{By Jessica Spencer and Uzo Chukwuma EpiData Center Department \\ January 2015}


MRSA Infections in the DOD: Annual Report 2013

NCMPHC-EDC-TR-44-2015

Prepared: December 2014

EpiData Center Department

\begin{tabular}{|c|c|c|c|c|c|c|}
\hline \multicolumn{5}{|c|}{ REPORT DOCUMENTATION PAGE } & & $\begin{array}{l}\text { Form Approved } \\
\text { OMB No. 0704-0188 }\end{array}$ \\
\hline \multicolumn{7}{|c|}{ 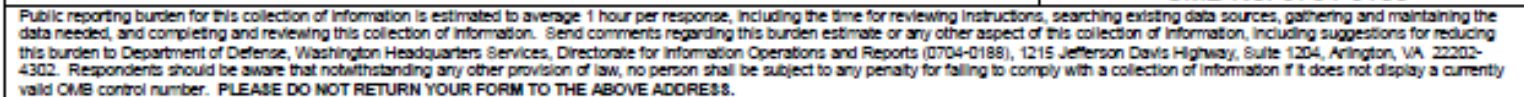 } \\
\hline \multirow{2}{*}{\multicolumn{4}{|c|}{ 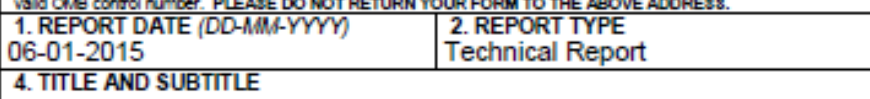 }} & & \multicolumn{2}{|r|}{$\begin{array}{l}\text { 3. DATES COVERED (From - To) } \\
01 \text { JAN } 2005-31 \text { DEC } 2013\end{array}$} \\
\hline & & & & 4. TITLE AND SUBTITLE & \multicolumn{2}{|c|}{ 5a. CONTRACT NUMBER } \\
\hline \multirow{2}{*}{\multicolumn{5}{|c|}{$\begin{array}{l}\text { Methicillin-Resistant Staphylococcus aureus (MRSA) Infections in the Department of } \\
\text { Defense (DOD): Annual Summary } 2013\end{array}$}} & \multicolumn{2}{|c|}{\begin{tabular}{|l|} 
5b. GRANT NUMBER \\
\end{tabular}} \\
\hline & & & & & \multicolumn{2}{|c|}{ 5c. PROGRAM ELEMENT NUMBER } \\
\hline \multirow{3}{*}{\multicolumn{5}{|c|}{$\begin{array}{l}\text { 6. AUTHOR(S) } \\
\text { Jessica Spencer, Uzo Chukwuma }\end{array}$}} & \multicolumn{2}{|c|}{ 5d. PROJECT NUMBER } \\
\hline & & & & & \multicolumn{2}{|c|}{ 5e. TASK NUMBER } \\
\hline & & & & & \multicolumn{2}{|c|}{ 5f. WORK UNIT NUMBER } \\
\hline \multicolumn{5}{|c|}{$\begin{array}{l}\text { 7. PERFORMING ORGANIZATION NAME(S) AND ADORESS(ES) } \\
\text { Navy and Marine Corps Public Health Center } \\
\text { EpiData Center Department } \\
620 \text { John Paul Jones Circle, Suite } 1100 \\
\text { Portsmouth, VA } 23708\end{array}$} & \multicolumn{2}{|c|}{$\begin{array}{l}\text { 8. PERFORMING ORGANIZATION REPORT } \\
\text { NUMBER } \\
\text { NMCPHC-EDC-TR-44-2015 }\end{array}$} \\
\hline \multirow{3}{*}{\multicolumn{5}{|c|}{$\begin{array}{l}\text { 9. SPONSORING / MONITORING AGENCY NAME(S) AND ADDRESS(ES) } \\
\text { Navy and Marine Corps Public Health Center } \\
\text { EpiData Center Department } \\
620 \text { John Paul Jones Circle, Suite } 1100 \\
\text { Portsmouth, VA } 23708\end{array}$}} & \multirow{2}{*}{\multicolumn{2}{|c|}{$\begin{array}{l}\text { 10. SPONSORMONITOR'S ACRONYM(S) } \\
\text { NMCPHC, EDC }\end{array}$}} \\
\hline & & & & & & \\
\hline & & & & & \multicolumn{2}{|c|}{$\begin{array}{l}\text { 11. SPONSORMMONITOR'S REPORT } \\
\text { NUMBER(S) } \\
\text { NMCPHC-EDC-TR-44-2015 }\end{array}$} \\
\hline \multicolumn{7}{|c|}{ 12. DISTRIBUTION / AVAILABILTY STATEMENT } \\
\hline \multicolumn{7}{|c|}{ Approved for Public Release. Distribution is not limited. } \\
\hline \multicolumn{7}{|c|}{ 13. SUPPLEMENTARY NOTES } \\
\hline \multicolumn{7}{|c|}{ 14. ABSTRACT } \\
\hline \multicolumn{7}{|c|}{$\begin{array}{l}\text { Methicillin-resistant Staphylococcus aureus (MRSA) infections are a national concern for public health and hospital officials due } \\
\text { to the opportunistic nature of the bacteria and the emergence of resistance to several antibiotics. In } 2013 \text {, the MRSA incidence } \\
\text { rates were } 58.7 \text { and } 73.0 \text { per } 100,000 \text { persons per year in the Department of Defense (DOD) and the Department of the Navy } \\
\text { (DON) beneficiary populations, respectively, this is a } 59 \% \text { decrease for the DOD and DON since } 2005 \text {. The majority of MRSA } \\
\text { infections within the DOD and DON in } 2013 \text { were outpatient, community-associated (CA), and skin and soft tissue infections } \\
\text { (SSTIs); similar patterns were observed since } 2005 \text {. In the DOD from } 2005-2013 \text {, MRSA isolates showed decreased } \\
\text { susceptibility to cefazolin. However, MRSA showed increased susceptibility to erythromycin and cefotaxime in both the DOD } \\
\text { and the DON, and to gentamicin in the DON only. The proportion of MRSA cases with inducible clindamycin resistance is } \\
\text { increasing, with a } 31.3 \% \text { increase in the DOD and a } 65.3 \% \text { increase in the DON from } 2005 \text { to } 2013 \text {. Military prescription } \\
\text { practices in } 2013 \text { were consistent with treatments recommended by the Infectious Diseases Society of America (IDSA). }\end{array}$} \\
\hline \multicolumn{7}{|c|}{ 15. SUBJECT TERMS } \\
\hline \multicolumn{7}{|c|}{ Health Level 7 (HL7), Microbiology, Surveillance, Methicillin-resistant Staphylococcus aureus (MRSA), inducible clindamycin resi } \\
\hline \multicolumn{3}{|c|}{$\begin{array}{l}\text { 16. SECURTYY CLASSIFICATION OF: } \\
\mathrm{U}\end{array}$} & $\begin{array}{l}\text { 17. LIMTATION } \\
\text { OF ABSTRACT }\end{array}$ & \multirow{2}{*}{\multicolumn{2}{|c|}{$\begin{array}{l}\text { 18. NUMBER } \\
\text { OF PAGES } \\
35\end{array}$}} & $\begin{array}{l}\text { 19a. NAME OF RESPONSIBLE PERSON } \\
\text { Uzo Chukwuma }\end{array}$ \\
\hline $\begin{array}{l}\text { a. REPORT } \\
\mathrm{U}\end{array}$ & $\begin{array}{l}\text { b. ABSTRACT } \\
\text { U }\end{array}$ & $\begin{array}{l}\text { c. THIS PAGE } \\
\mathrm{U}\end{array}$ & Uu & & & $\begin{array}{l}\text { 19b. TELEPHONE NUMBER (include area } \\
\text { code) } \\
757-953-0706\end{array}$ \\
\hline
\end{tabular}




\section{Abstract}

Methicillin-resistant Staphylococcus aureus (MRSA) infections are a national concern for public health and hospital officials due to the opportunistic nature of the bacteria and the emergence of resistance to several antibiotics. In 2013, the MRSA incidence rates were 58.7 and 73.0 per 100,000 persons per year in the Department of Defense (DOD) and the Department of the Navy (DON) beneficiary populations, respectively; this is a 59\% decrease for the DOD and DON since 2005. The majority of MRSA infections within the DOD and DON in 2013 were outpatient, community-associated (CA), and skin and soft tissue infections (SSTIs); similar patterns were observed since 2005. In the DOD from 2005 - 2013, MRSA isolates showed decreased susceptibility to cefazolin. However, MRSA showed increased susceptibility to erythromycin and cefotaxime in both the DOD and the DON, and to gentamicin in the DON only. The proportion of MRSA cases with inducible clindamycin resistance is increasing, with a $31.3 \%$ increase in the DOD and a $65.3 \%$ increase in the DON from 2005 to 2013. Military prescription practices in 2013 were consistent with treatments recommended by the Infectious Diseases Society of America (IDSA). 
MRSA Infections in the DOD: Annual Report 2013

NCMPHC-EDC-TR-44-2015

Prepared: December 2014

EpiData Center Department

\section{Table of Contents}

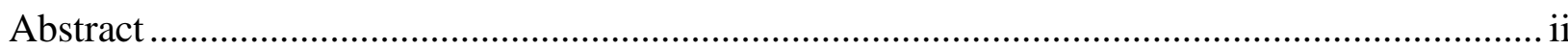

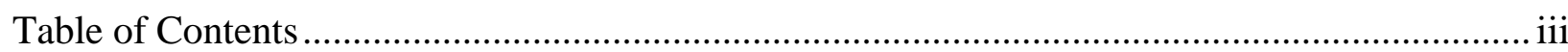

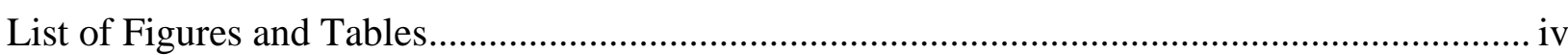

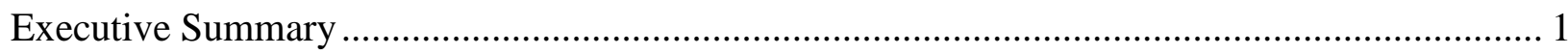

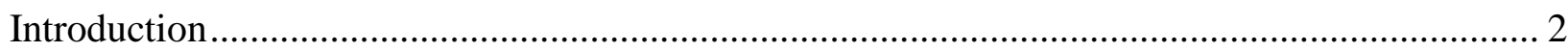

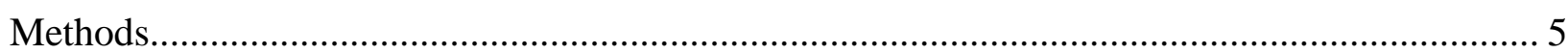

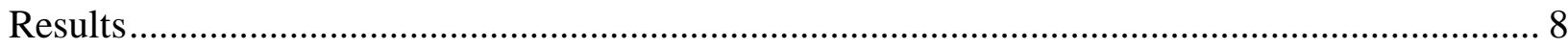

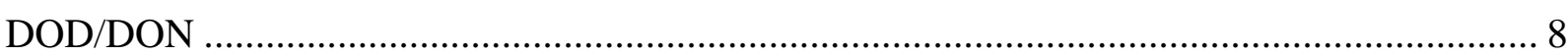

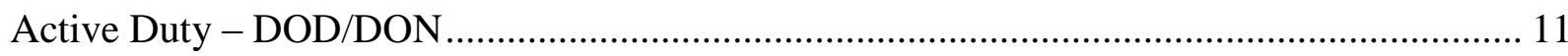

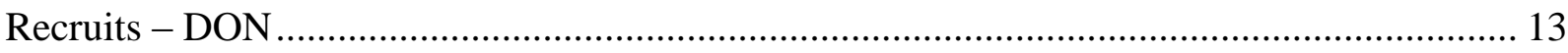

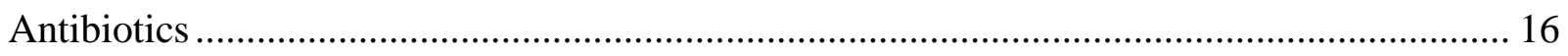

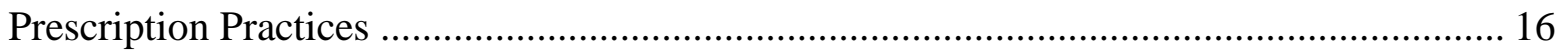

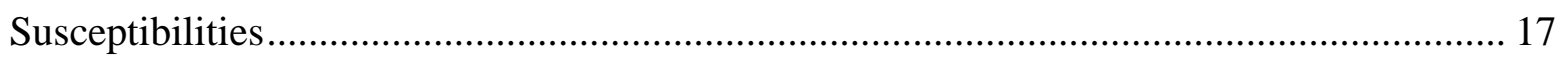

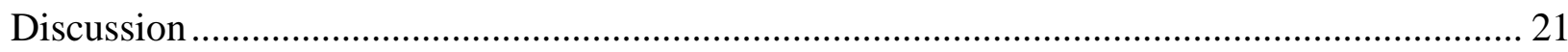

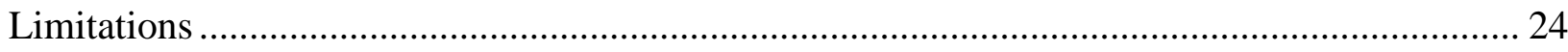

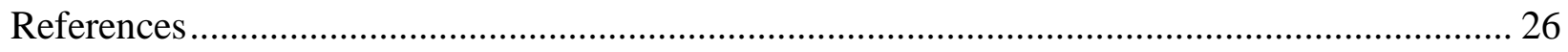

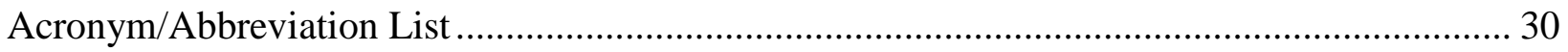




\section{List of Figures and Tables}

Figure 1. MRSA Incidence Rates Among DOD Beneficiaries, CY 2005 - 2013 .................... 10

Figure 2. MRSA Incidence Rates Among DON Beneficiaries, CY 2005 - 2013 ..................... 10

Figure 3. MRSA Incidence Rates in DOD Beneficiaries by Month, CY 2007 - 2013 ............. 10

Figure 4. MRSA Incidence Rates in DON Beneficiaries by Month, CY 2007 - 2013 .............. 10

Figure 5. MRSA Incidence Rates Among DOD Active Duty Service Members, CY 2005 - 2013

Figure 6. MRSA Incidence Rates Among DON Active Duty Service Members, CY 2005 - 2013

Figure 7. Incidence Rates of MRSA Infections Occurring During Basic Training in DON

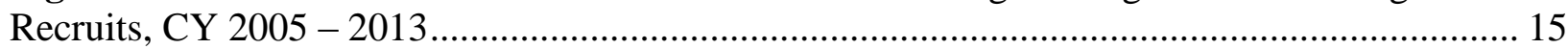

Figure 8. Proportion of MRSA Prevalence in DON Recruits Identified During Each Week of Recruit Training, CY 2005 - 2013 ........................................................................................ 16

Figure 9. Percentage of MRSA Isolates with Inducible Clindamycin Resistance ${ }^{\mathrm{a}}$ in the DOD and

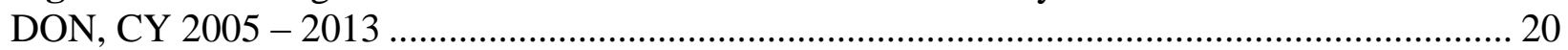

Table 1. Infection Classification for MRSA Cases Accessing the Military Health System ......... 5

Table 2. Demographic Description of MRSA Prevalence Among DOD and DON Beneficiaries, CY $2005-2013$

Table 3. Clinical Characteristics of MRSA Prevalence Among DOD and DON Beneficiaries, CY $2005-2013$.

Table 4. Demographic Description of MRSA Prevalence Among DOD and DON Active Duty Beneficiaries, CY 2005 - 2013.

Table 5. Clinical Characteristics of MRSA Prevalence Among DOD and DON Active Duty

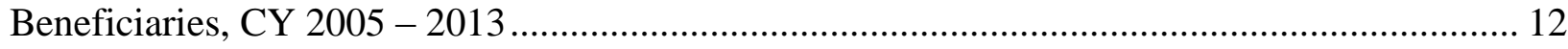

Table 6. Demographics of DON Recruit MRSA Prevalence, CY 2005 - 2013 ....................... 13

Table 7. Clinical Characteristics of DON Recruit MRSA Prevalence, CY 2005 - 2013 ........... 14

Table 8. Antibiotic Prescriptions Associated with DOD and DON MRSA Infections, CY 2006 2013.

Table 9. Antibiotic Susceptibilities of MRSA Cases within the DOD Population, CY 2005 $2013^{\mathrm{a}}$

Table 10. Antibiotic Susceptibilities of MRSA Isolates within the DON Population, CY 2005 $2013^{\mathrm{a}}$ 


\section{Executive Summary}

The EpiData Center Department (EDC) at the Navy and Marine Corps Public Health Center (NMCPHC) conducts routine surveillance of clinically significant organisms within the Department of Defense (DOD) and the Department of the Navy (DON) beneficiary populations. This report provides a summary of Methicillin-resistant Staphylococcus aureus (MRSA) incidence and prevalence in calendar year (CY) 2013 and describes the demographics, clinical characteristics, prescription practices, and antibiotic resistance patterns observed among all DOD and DON beneficiaries and separately among DOD and DON active duty (AD) service members, and DON recruits.

The linking of several data sources in this report allows for the assessment of a variety of unique descriptive and clinical factors related to MRSA within multiple populations. Health Level 7 (HL7) formatted microbiology data identified $S$. aureus cases resistant to oxacillin, cefoxitin, or methicillin, classifying these isolates as MRSA. These isolates were matched to HL7 formatted pharmacy data to assess prescription practices, the Standard Inpatient Data Record (SIDR) database to determine healthcare-associated exposures, and the Defense Manpower Data Center (DMDC) AD roster to determine the burden of MRSA among DON recruits.

Overall, the incidence rates of MRSA in the general United States (US) population, the DOD and DON beneficiary populations, and the DOD and DON AD and recruit populations are decreasing. Inducible clindamycin resistance, however, shows a slow increase in the DOD and DON since 2005; however, no additional changes in antibiotic susceptibility were identified in 2013. Clindamycin, trimethoprim/sulfamethoxazole, doxycycline, and vancomycin remain viable treatments for MRSA, although clindamycin should be used with caution in the inpatient setting due to reduced susceptibility. Current infection control practices appear to have an impact on reducing the overall burden of MRSA, improving mission readiness through a healthy fleet and force. However, continued surveillance is required to monitor any changes in burden, susceptibility, and treatment options. 


\section{Introduction}

S. aureus is a common gram-positive bacterium. MRSA is a specific type of Staphylococcus bacteria that has developed resistance to $\beta$-lactam antibiotics such as methicillin, oxacillin, and penicillin $^{1-5}$ thus causing difficulty in treatment of the infection. MRSA infections have been a national concern for public health and hospital officials due to the opportunistic nature of the bacteria and the limited treatment options available as a result of the emergence of antibiotic resistance. Surveillance of MRSA is important to ensure effective antibiotic stewardship and to monitor mutations that may alter treatment options.

MRSA is known for its ease in transmission. MRSA spreads from person to person through contaminated objects or casual contact. MRSA typically presents in three forms: colonization, non-invasive infection, and invasive infection. MRSA is a common colonizer of the nares, axillae, vagina, and pharynx. Colonization often serves as a reservoir from which bacteria can cause infection. ${ }^{6,7}$ Non-invasive infections account for the majority of MRSA infections and generally manifest as skin or soft tissue infections (SSTIs) in locations where skin integrity is compromised (e.g., cuts, abrasions) or covered by hair. ${ }^{8}$ Invasive infections, though less common, occur when these bacteria invade the bloodstream, resulting in bacteremia that can lead to endocarditis, sepsis, or other invasive infections, which may be fatal. ${ }^{9}$ Efforts to reduce the spread of MRSA in recent years focused on the screening and decolonization of select groups of hospitalized patients, such as intensive care unit (ICU) patients, using intranasal mupirocin and chlorahexidine bathing. ${ }^{10}$

MRSA strains commonly identified in healthcare facilities are different from those found in the community setting and each of these settings has unique risk factors. Healthcare-associated (HA) MRSA infections occur when a patient has a history of hospitalization within the 12 months prior to the current admission, during which a MRSA infection has developed. Among HA MRSA infections, the common risk factors include advanced age, weakened immune system, hospitalization, residence in a long-term care facility, or use of an invasive medical device. MRSA is the leading cause of HA infections among antibiotic resistant organisms ${ }^{11,12}$ and these infections lead to a significant burden on hospital resources. Recent estimates suggest that up to $65 \%$ of HA $S$. aureus infections are caused by methicillin-resistant strains. ${ }^{13}$ Hospital onset (HO) MRSA infections occur when a patient is admitted without a MRSA infection, but subsequently develops a MRSA infection three or more days after the admission date. HA and HO MRSA infections are typically more severe or potentially life threatening than communityassociated (CA) MRSA, and examples include bacteremia or infections occurring at the site of a surgical wound. Fortunately, these invasive $\mathrm{HA}$ and $\mathrm{HO}^{13}$ MRSA infections appear to have declined in recent years. In 2012, the Centers for Disease Control and Prevention (CDC) estimated the overall infection rate of invasive MRSA in the US to be approximately 23.9 cases per 100,000 persons in the general population, with a death rate of approximately 3.1 per 100,000 persons. $^{14}$ These rates reflect a decrease from 2005, when the infection rate was estimated to be 35.5 cases per 100,000 persons in the general population, with a death rate of 6.8 per 100,000 persons. ${ }^{15}$ 
MRSA in the community setting was not a common occurrence until the late 1990's. Since then, CA MRSA infections have emerged ${ }^{11}$ increasingly among individuals with no recent healthcare contact or other apparent risk factors. CA MRSA outbreaks have been reported in environments with intense physical activity and skin-to-skin contact, such as is common among military recruits, prison inmates, and athletic teams. ${ }^{16}$ The CDC has identified that between $12-14 \%$ of MRSA infections are CA. ${ }^{17,18}$ CA MRSA is most often identified as an SSTI, and while rates of non-invasive MRSA infections are not available for comparison in a similar nationwide scale, a study of 11 emergency departments in the US found MRSA was the cause of 59\% of SSTIs overall, making it a prominent cause of SSTIs in the community setting. ${ }^{19}$

Seasonal variations in $S$. aureus infections also occur, with some studies reporting an increase in infections during the summer months of most climates and the fall months of temperate and tropical climatic regions. ${ }^{20-24}$ However, reports on the seasonality of MRSA infections are disputed, as many of the reports focus primarily on SSTIs. Increased incidence of S. aureus during the warmer months may be attributed to conducive environmental conditions (e.g., warm temperatures) that promote bacterial growth and spread of infection. ${ }^{24}$

In January 2013, the Infectious Disease Society of America (IDSA) published updated clinical practice guidelines for the treatment of MRSA infections according to the treatment setting (inpatient or outpatient) and infection type (SSTI, bacteremia, pneumonia, and other invasive infections). General treatment for MRSA SSTIs may include oral antibiotics such as clindamycin, trimethoprim/sulfamethoxazole, doxycycline, or minocycline. For more complicated SSTIs, intravenous vancomycin or linezolid is recommended. ${ }^{25,26}$ Vancomycin or daptomycin are recommended for uncomplicated MRSA bacteremia and other invasive infections. In the case of vancomycin resistance, high-dose intravenous daptomycin in combination with gentamicin, rifampin, or linezolid is suggested. For cases with less susceptibility to both vancomycin and daptomycin, therapeutic options include intravenous quinupristin-dalfopristin, intravenous trimethoprim-sulfamethoxazole, intravenous or oral linezolid, or intravenous telavancin. ${ }^{26}$ Treatment options for CA MRSA infections may differ from HA MRSA infections, as CA MRSA infections often do not possess the same level of multidrug-resistance (MDR) as HA MRSA infections. The greater susceptibility of CA MRSA infections has led to the reappearance of older antibiotic classes for management of these infections, such as lincosamides and macrolides. CA MRSA infections are often susceptible to trimethoprim/sulfamethoxazole, clindamycin, doxycycline or minocycline, and fluoroquinolones; however, susceptibility patterns may vary by geographic region. ${ }^{27}$

Treatment of MRSA infections can be complicated by the susceptibility of $S$. aureus to available antibiotics. Per the IDSA clinical practice guidelines, clindamycin is commonly used to treat MRSA and is more cost efficient than newer antibiotic drugs, such as linezolid and daptomycin. $^{27}$ Since the early 2000s, concerns have risen over the possibility for inducible clindamycin resistance, which occurs when organisms have the genetic potential to become resistant to clindamycin during the course of treatment, thereby causing treatment failures and enhancing the virulence of the MRSA pathogen. ${ }^{27}$ Reports from several studies identify 18 $52 \%$ of all S. aureus isolates have induced clindamycin resistance. ${ }^{28,29}$ The expression of induced clindamycin resistance is only detected through the use of agar disk diffusion (D-test) in 
accordance with recommendations from the Clinical and Laboratory Standards Institute (CLSI). ${ }^{30}$ Additionally, vancomycin is generally restricted for use in severe MRSA infections as an antibiotic of last resort. The increased use and misuse of vancomycin to treat MRSA propagates the mechanism of resistance and allows for changes in virulence and resistance patterns of $S$. aureus, leading to vancomycin-resistant $S$. aureus (VRSA) infections. Although VRSA infections are quite rare and none have been identified in the US military yet, it is concerning that seven strains of VRSA have been isolated in the US since $2002 .{ }^{31}$ Careful consideration and close monitoring of antibiotics used to treat MRSA is needed to ensure continued susceptibility of $S$. aureus to available antibiotics.

MRSA also poses a threat for the US military due to environmental and occupational exposures that may facilitate transmission of infections and compromise force health and operational readiness. Outbreaks have occasionally occurred among military trainees. ${ }^{32}$ Although rates of HA MRSA infection among AD personnel have declined in recent years, this population remains at significant risk for CA MRSA due to environmental and occupational exposures such as combat-associated deployments. ${ }^{33,34}$ Some studies have shown that during military training, approximately $5 \%$ of all individuals will experience an SSTI, with S. aureus isolated in $91 \%$ of these cases, and MRSA identified in $70 \%$ of the Staphylococcus infections. ${ }^{34-36}$

It is important, therefore, to monitor MRSA trends and changes in epidemiology on an ongoing basis. This analysis presents an annual update of MRSA infection burden among DOD and DON beneficiaries. This update compares the 2013 results to historical trends from 2005 to 2012 as a reference for assessing the current year's burden. 


\section{Methods}

This report covers the surveillance period from January 1, 2005 through December 31, 2013. The EDC at the NMCPHC receives daily microbiology data in the HL7 format that originates from the Composite Health Care System (CHCS) at fixed military treatment facilities (MTFs), hereafter referred to as HL7 microbiology data. These data do not include records from purchased care providers, shipboard facilities, battalion aid stations, or in-theater facilities. The HL7 microbiology data were used to identify records with $S$. aureus growth occurring from 2005 through 2013. S. aureus isolates resistant to oxacillin, cefoxitin, or methicillin were classified as MRSA. A unique MRSA infection was defined as the first MRSA isolate per person per month. Incidence represents the first unique infection per person per calendar year and prevalence was defined as all unique MRSA infections. For this report, isolates collected from surveillance sources (nares, groin, or axilla specimens) were removed from analysis, as these isolates are typically indicative of colonization and not true infection. MRSA infections were categorized into SSTIs, invasive infections, non-invasive infections, and unknown categories. These categories are described in Table 1.

\begin{tabular}{|c|c|}
\hline Infection Classification & If Body Site or Specimen Source Sample Taken From: \\
\hline $\begin{array}{l}\text { Skin and Soft Tissue } \\
\text { Infections (SSTIs) }\end{array}$ & $\begin{array}{l}\text { Abscess, boil, carbuncle, cellulitis, cyst, discharge, drainage, } \\
\text { exudate, lesion, pus, pustule, skin, or wound }\end{array}$ \\
\hline Invasive Infections & $\begin{array}{l}\text { Blood, bone, cerebrospinal fluid, peritoneal fluid, pleural fluid, or } \\
\text { synovial fluid }\end{array}$ \\
\hline $\begin{array}{l}\text { Other Non-Invasive } \\
\text { Infections }\end{array}$ & $\begin{array}{l}\text { Aspirate, body fluid, bursa, cyst, eye, genital, respiratory, sputum, } \\
\text { stool, swab, throat, tissue, or urine }\end{array}$ \\
\hline Unknown & $\begin{array}{l}\text { No identifiable information regarding the specimen collection } \\
\text { site contained in the record }\end{array}$ \\
\hline \multicolumn{2}{|c|}{$\begin{array}{l}\text { Prepared by the EpiData Center Department, Navy and Marine Corps } \\
\text { Public Health Center, on } 02 \text { October } 2014 \text {. }\end{array}$} \\
\hline
\end{tabular}

To assess healthcare exposure for the study population, the HL7 microbiology MRSA records were matched to the SIDR database using unique patient identifiers and the specimen collection date. Three categories of healthcare exposure included: HO, HA, and CA. An infection was considered HO if the specimen was collected at least four days after the hospital admission date. An infection was considered HA if the individual had a history of hospitalization within the 12 months prior to the specimen collection date for the current infection. ${ }^{4}$ An infection was classified as CA if the specimen was collected within three days of the inpatient admission date, and if there were no other hospitalization records in the 12 months prior to the date of the current MRSA isolate; these conditions indicate that the patient arrived at the MTF with the infection and the infection was not linked to prior healthcare exposures.

To analyze antibiotic prescription practices, the HL7 microbiology MRSA records were matched to pharmacy data to identify antibiotic prescriptions associated with MRSA infections in the outpatient oral (OP), inpatient oral (unit dose, or UD), and inpatient and outpatient intravenous (IV) databases. Pharmacy data were available for OP beginning in 2006; UD and IV data were 
available from 2009 forward. Prescriptions were considered related to a MRSA infection if the transaction date in the pharmacy record occurred up to seven days after the specimen collection date.

To evaluate changes in susceptibility for MRSA infections, an antibiogram was created using antibiotic susceptibility results from the microbiology record according to the CLSI guidelines. ${ }^{37}$ The antibiogram includes the first isolate per person per year from $2005-2013$. Antibiotics selected for the antibiogram were based on the 2013 IDSA Clinical Practice Guidelines. ${ }^{37}$ The Cochran-Armitage trend test was used to assess patterns in susceptibility across years. Additional analyses were conducted to assess trend, demographic, and clinical characteristics of isolates that exhibit inducible clindamycin resistance. Inducible clindamycin resistance was determined only when the susceptibility results indicated both erythromycin and clindamycin resistance.

AD status was defined by the beneficiary type code ' 11 ' and recruit duty status was defined by the beneficiary type code ' 13 ' in the HL7 microbiology record. Beneficiaries with recruit status were also matched to the DMDC AD roster to determine each recruit's training center, unit identification code (UIC), and training period. The timeframe of recruit training was estimated using the federal service start date in DMDC as the estimated start of recruit training. The standard recruit training period of 9 weeks was added to the start date for Navy recruits and 13 weeks was added to the start date for Marine Corps recruits to estimate the end date of recruit training. Infections associated with recruit status were identified if the microbiology specimen collection dates occurred during the recruit training period or within seven days following the end of recruit training.

The Military Health System (MHS) Data Mart (M2) was used to obtain counts of TRICARE eligible DOD and DON beneficiaries for denominators. The monthly incidence rate represents the monthly count of unique infections per year divided by the corresponding monthly M2 eligible beneficiary counts per year from $2007-2013$. The annual prevalence rate was defined as the count of all unique infections each year divided by the corresponding annual M2 eligible beneficiary count (represented by count in July) per year. Denominators for infection rates in DON recruits were calculated using a DMDC recruit roster generated by the EDC for each year. Historical rates were calculated using data from 2005 - 2012. All rates are presented as an estimated rate per 100,000 persons per year. Due to the transient nature of the military beneficiary population and an inability to account for the proportion of the beneficiary population that receives medical care outside of the MHS, estimated rates are used for comparison of rates from year to year. Overall trends in infection rates are described using average annual percentage changes from $2005-2013$.

To establish a consistent process to identify unnatural variation in annual incidence rates, the Statistical Process Control (SPC) method was used. ${ }^{38}$ A mean, also described as the Center Line (CL), was calculated using at least two years of data. The Upper Control Limit (UCL), known as the upper limit of natural variation, and the Lower Control Limit (LCL), known as the lower limit of natural variation, were calculated as three standard deviations above and below the mean (CL), respectively. An annual rate that falls outside of the UCL or LCL has unnatural variation. 
MRSA Infections in the DOD: Annual Report 2013

NCMPHC-EDC-TR-44-2015

Prepared: December 2014

EpiData Center Department

If unnatural variation occurs over several years, then the mean is reset to establish a more consistent process. For this report, the mean was reset in 2010 due to unnatural variation in MRSA incidence with a significant reduction in cases. The first mean was calculated for CY 2005 - 2009; the second mean was calculated for CY 2010 - 2013. 


\section{Results}

\section{All Beneficiaries - DOD/DON}

In 2013, there were 5,871 unique MRSA infections identified among all DOD beneficiaries who were treated at an MTF, with 2,228 unique infections identified within the DON. In 2013, the highest prevalence rates among each demographic category for both the DOD and DON occurred in 18 - 24 year olds, males, Marine Corps beneficiaries, AD service members, and beneficiaries seen outside the continental US (OCONUS) TRICARE region (Table 2). These same patterns occurred historically in both the DOD and DON.

Table 2. Demographic Description of MRSA Prevalence Among DOD and DON

Beneficiaries, CY $2005-2013$

\begin{tabular}{|c|c|c|c|c|c|c|c|c|}
\hline & \multicolumn{4}{|c|}{ DOD } & \multicolumn{4}{|c|}{ DON } \\
\hline & \multicolumn{2}{|c|}{$2013(N=5,871)$} & \multicolumn{2}{|c|}{ Historic $(\mathrm{N}=101,859)$} & \multicolumn{2}{|c|}{$2013(N=2,228)$} & \multicolumn{2}{|c|}{ Historic $(\mathrm{N}=36,931)$} \\
\hline & Count & Rate & Count & Rate & Count & Rate & Count & Rate \\
\hline \multicolumn{9}{|l|}{ Gender $^{\mathrm{a}}$} \\
\hline Female & 2,076 & 45.4 & 34,236 & 95.7 & 706 & 52.4 & 11,075 & 102.8 \\
\hline Male & 3,795 & 80.0 & 67,622 & 178.5 & 1,522 & 103.9 & 25,856 & 215.4 \\
\hline \multicolumn{9}{|c|}{ Age Group (in Years) } \\
\hline $0-17$ & 1,142 & 58.2 & 18,078 & 113.6 & 396 & 69.4 & 6,065 & 124.5 \\
\hline $18-24$ & 1,896 & 158.8 & 40,842 & 407.4 & 874 & 201.5 & 17,355 & 462.4 \\
\hline $25-34$ & 1,201 & 101.5 & 18,977 & 219.0 & 409 & 114.3 & 6,233 & 229.3 \\
\hline $35-44$ & 469 & 57.5 & 8,339 & 116.4 & 157 & 63.8 & 2,613 & 117.6 \\
\hline $45-64$ & 688 & 32.9 & 9,545 & 56.1 & 232 & 37.0 & 3,045 & 67.5 \\
\hline $65+$ & 475 & 23.0 & 6,078 & 40.8 & 160 & 27.8 & 1,620 & 38.3 \\
\hline \multicolumn{9}{|l|}{ Sponsor Service } \\
\hline Air Force & 944 & 36.3 & 15,080 & 72.6 & & & & \\
\hline Army & 2,699 & 69.2 & 49,848 & 172.7 & & & & \\
\hline Marine Corps & 858 & 114.1 & 15,993 & 272.0 & 858 & 114.1 & 15,993 & 272.0 \\
\hline Navy & 1,370 & 66.5 & 20,938 & 123.9 & 1,370 & 66.5 & 20,938 & 123.9 \\
\hline \multicolumn{9}{|c|}{ Beneficiary Type } \\
\hline Active Duty & 2,589 & 184.8 & 51,109 & 449.2 & 1,132 & 217.5 & 21,244 & 496.0 \\
\hline Dependent & 2,351 & 47.6 & 36,041 & 92.5 & 812 & 52.7 & 11,969 & 95.0 \\
\hline Retired & 649 & 31.2 & 8,588 & 53.4 & 232 & 37.2 & 2,676 & 54.3 \\
\hline Other & 282 & 31.5 & 6,121 & 84.5 & 52 & 41.4 & 1,042 & 106.6 \\
\hline \multicolumn{9}{|l|}{ TRICARE Region } \\
\hline North & 1,469 & 51.4 & 27,846 & 118.8 & 754 & 72.8 & 13,375 & 158.9 \\
\hline OCONUS & 460 & 123.6 & 6,860 & 198.6 & 164 & 164.1 & 2,195 & 272.5 \\
\hline South & 2,027 & 66.6 & 39,291 & 168.5 & 543 & 78.7 & 9,254 & 165.4 \\
\hline West & 1,767 & 61.8 & 27,270 & 122.6 & 745 & 80.3 & 11,857 & 157.4 \\
\hline Unknown $^{\mathrm{b}}$ & 148 & & 592 & & 22 & & 250 & \\
\hline \multirow{3}{*}{\multicolumn{9}{|c|}{$\begin{array}{l}\text { ane record had an "Unknown" gender classification in } 2005 \text { and was excluded. } \\
\text { b TRICARE service region cannot be identified from the microbiology record. } \\
\text { Rates are presented as the rate per } 100,000 \text { persons per year. } \\
\text { Data Source: NMCPHC HL7 formatted microbiology and Standard Inpatient Data Record } \\
\text { (SIDR) databases. }\end{array}$}} \\
\hline & & & & & & & & \\
\hline & & & & & & & & \\
\hline \multicolumn{9}{|c|}{$\begin{array}{l}\text { Prepared by the EpiData Center De } \\
\text { Center, on } 13 \text { November } 2014 .\end{array}$} \\
\hline
\end{tabular}

In the DOD and DON in 2013, the largest proportions of infections appeared in the outpatient setting as CA infections (Table 3), this is similar to historical patterns. Overall, $71.4 \%$ and $67.1 \%$ of all MRSA infections in 2013 were from sources indicative of an SSTI for the DOD and 
DON, respectively. Among these SSTIs, most MRSA specimen sources were identified as wounds $(\mathrm{DOD}=57.5 \% ; \mathrm{DON}=51.2 \%)$ or abscesses $(\mathrm{DOD}=22.2 \% ; \mathrm{DON}=24.4 \%)$. Of all invasive MRSA infections in 2013, blood isolates accounted for $83.1 \%$ and $85 \%$ of infections for the DOD and DON, respectively (data not shown). Similar proportions exist in the historical data from $2005-2012$, with wounds (DOD $=54.6 \%$; DON $=50.5 \%)$ and abscesses (DOD $=22.9 \%$; DON $=25.1 \%$ ) being the most commonly identified SSTIs, and blood (DOD $=84.3 \%$; DON = $80.4 \%$ ) being the most commonly identified source for invasive MRSA infections (data not shown).

\begin{tabular}{|c|c|c|c|c|c|c|c|c|}
\hline & \multicolumn{4}{|c|}{ DOD } & \multicolumn{4}{|c|}{ DON } \\
\hline & \multicolumn{2}{|c|}{$2013(N=5,871)$} & \multicolumn{2}{|c|}{ Historic $(\mathrm{N}=101,859)$} & \multicolumn{2}{|c|}{$2013(N=2,228)$} & \multicolumn{2}{|c|}{ Historic $(\mathrm{N}=36,931)$} \\
\hline & Count & Percentage & Count & Percentage & Count & Percentage & Count & Percentage \\
\hline \multicolumn{9}{|l|}{ Encounter Type } \\
\hline Inpatient & 542 & 9.2 & 7,872 & 7.7 & 204 & 9.2 & 2,545 & 6.9 \\
\hline Outpatient & 5,329 & 90.8 & 93,987 & 92.3 & 2,024 & 90.8 & 34,386 & 93.1 \\
\hline \multicolumn{9}{|l|}{ Healthcare Exposure ${ }^{a}$} \\
\hline Hospital onset ( $\mathrm{HO})$ & 95 & 1.6 & 1,982 & 1.9 & 36 & 1.6 & 563 & 1.5 \\
\hline Healthcare-associated (HA) & 886 & 15.1 & 13,724 & 13.5 & 331 & 14.9 & 4,443 & 12.0 \\
\hline Community-associated (CA) & 4,953 & 84.4 & 87,496 & 85.9 & 1,883 & 84.5 & 32,263 & 87.4 \\
\hline \multicolumn{9}{|l|}{ Specimen Type } \\
\hline Skin and Soft Tissue Infection (SSTI) & 4,193 & 71.4 & 76,606 & 75.2 & 1,494 & 67.1 & 26,383 & 71.4 \\
\hline Invasive & 130 & 2.2 & 1,620 & 1.6 & 53 & 2.4 & 509 & 1.4 \\
\hline Other non-invasive & 1,449 & 24.7 & 22,092 & 21.7 & 620 & 27.8 & 9,350 & 25.3 \\
\hline Unknown & 99 & 1.7 & 1,541 & 1.5 & 61 & 2.7 & 689 & 1.9 \\
\hline \multicolumn{9}{|c|}{$\begin{array}{l}\text { A single MRSA isolate can be classified as more than one healthcare- or communit } \\
\text { associated exposure, therefore the counts may be greater than the total N. } \\
\text { Data Source: NMCPHC HL7 formatted microbiology and Standard Inpatient Data Re } \\
\text { (SIDR) databases. } \\
\text { Prepared by the EpiData Center Department, Navy and Marine Corps Public Health } \\
\text { Center, on } 04 \text { November } 2014 \text {. }\end{array}$} \\
\hline
\end{tabular}

The DOD annual incidence rates for the first surveillance time period (2005 - 2009) ranged from 135.5 to 160.3 , with an average incidence rate of 148.4 per 100,000 persons per year. In the DON, the annual incidence rates for the first surveillance time period (2005 - 2009) ranged from 154.8 to 198.9 , with an average incidence rate of 176.8 per 100,000 persons per year. During this time period, the incidence rates fluctuated around the historical mean with an overall decreasing trend in both the DOD and DON (Figures 1 and 2). Substantial peaks in incidence rate that were outside the natural variation occurred in 2006 for both the DOD and DON, and in 2008 for only the DOD. Trends in the second surveillance time period $(2010-2013)$ were quite different from trends in the first time period. In the second time period, the DOD annual incidence rates ranged from 58.7 to 109.6 , with an average incidence rate of 82.3 per 100,000 persons per year. In the DON, the annual incidence rates for the second surveillance time period ranged from 73.0 to 122.5 , with an average incidence rate of 93.8 per 100,000 persons per year. An overall decreasing trend emerged for the entire second time period with a $46.5 \%$ decrease in the DOD and a $40.4 \%$ decrease in the DON. Incidence rates in the last two years for this period were below the historic mean and outside the natural variation for expected rates for both the DOD and DON populations. Incidence rates in 2013 were the lowest rates documented for both surveillance periods for the DOD and DON. 


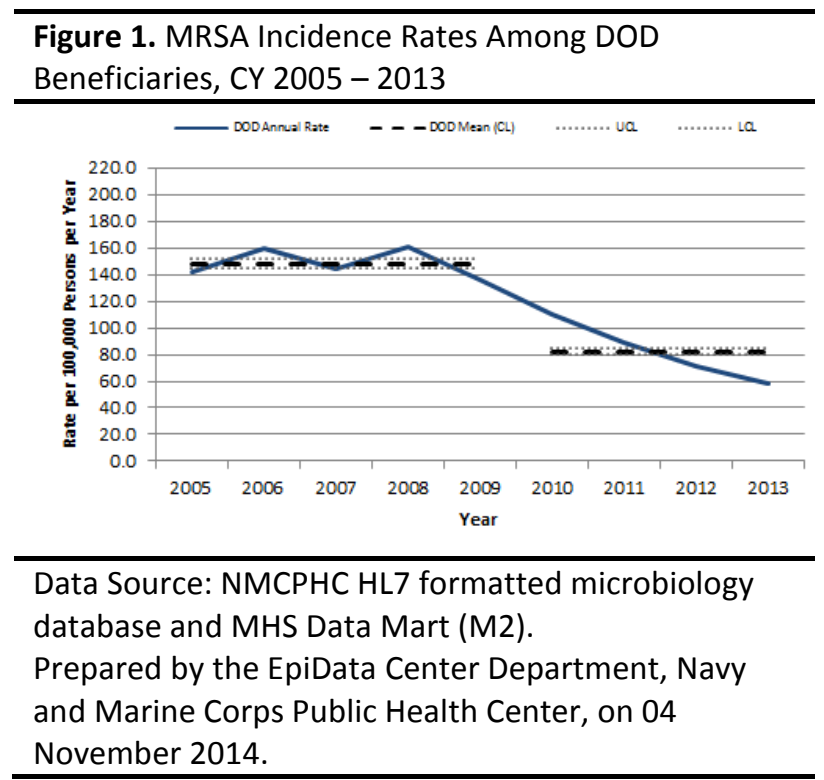

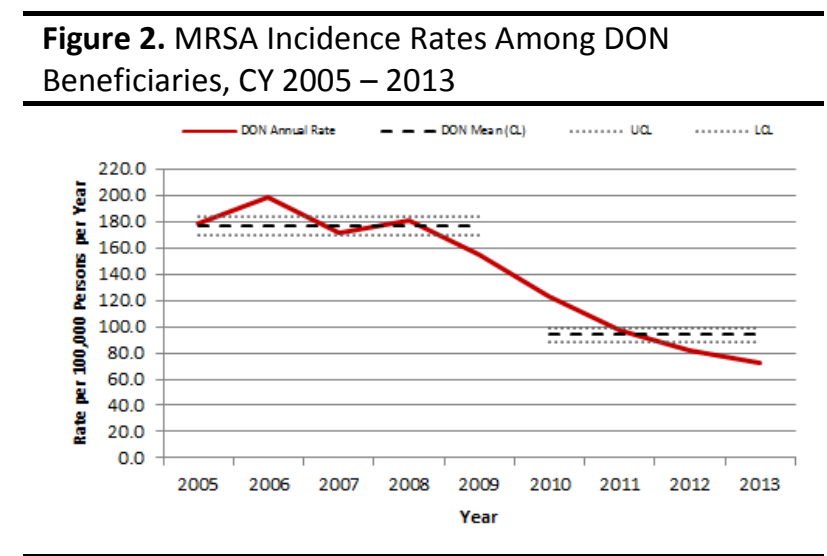

Data Source: NMCPHC HL7 formatted microbiology database and MHS Data Mart (M2).

Prepared by the EpiData Center Department, Navy and Marine Corps Public Health Center, on 04 November 2014.

DOD and DON monthly incidence rates in 2013 were the lowest since enterprise-wide surveillance began in 2005 (Figures 3 and 4). Incidence rates for 2013 for both DOD and DON beneficiaries exhibited a slight deviation from the seasonal trends of previous years. Historically with the exception of 2007, the highest rates occurred in the third quarter, peaking in August; in contrast, the 2013 rates peaked in the latter part of the third quarter in September.

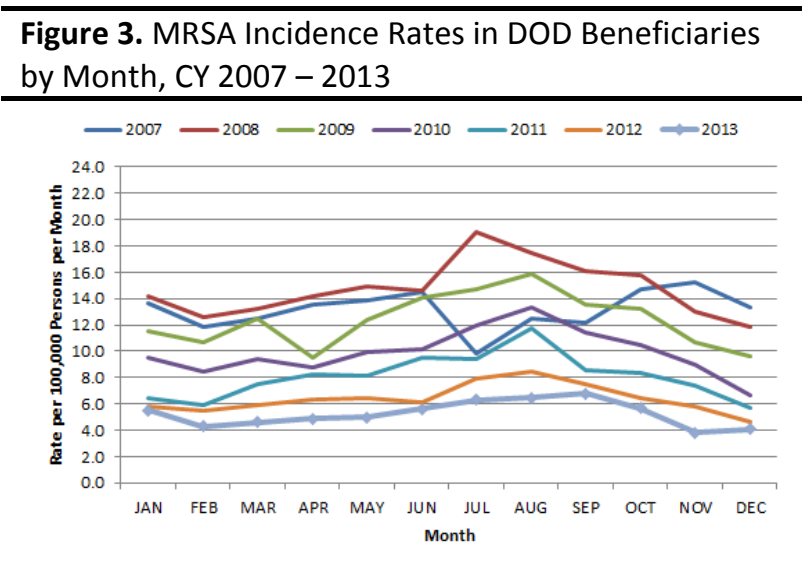

Data Source: NMCPHC HL7 formatted microbiology database and MHS Data Mart (M2).

Prepared by the EpiData Center Department, Navy and Marine Corps Public Health Center, on 04 November 2014.

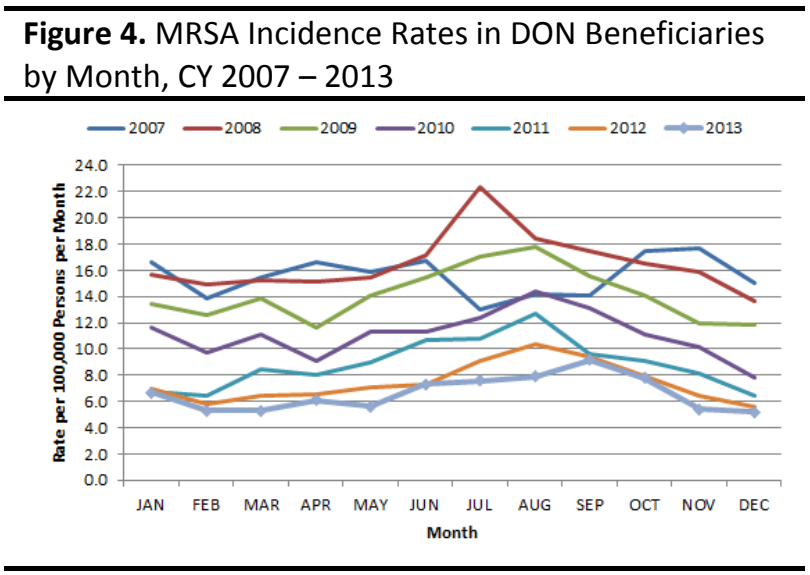

Data Source: NMCPHC HL7 formatted microbiology database and MHS Data Mart (M2).

Prepared by the EpiData Center Department, Navy and Marine Corps Public Health Center, on 04 November 2014. 
As has been the historical trend, infections among DOD and DON AD service members in 2013 were mostly identified in the outpatient setting, classified as CA, and diagnosed as SSTIs. Less than one percent of AD MRSA infections in the DOD and DON were from invasive specimen sources in 2013, a pattern also observed in the historical data (Table 5).

\begin{tabular}{|c|c|c|c|c|c|c|c|c|}
\hline & \multicolumn{4}{|c|}{ DOD } & \multicolumn{4}{|c|}{ DON } \\
\hline & \multicolumn{2}{|c|}{$2013(N=2,589)$} & \multicolumn{2}{|c|}{ Historic $(N=51,109)$} & \multicolumn{2}{|c|}{$2013(N=1,132)$} & \multicolumn{2}{|c|}{ Historic $(N=21,244)$} \\
\hline & Count & Percentage & Count & Percentage & Count & Percentage & Count & Percentage \\
\hline \multicolumn{9}{|l|}{ Encounter Type } \\
\hline Inpatient & 127 & 4.9 & 2,140 & 4.2 & 51 & 4.5 & 848 & 4.0 \\
\hline Outpatient & 2,462 & 95.1 & 48,969 & 95.8 & 1,081 & 95.5 & 20,396 & 96.0 \\
\hline \multicolumn{9}{|l|}{ Healthcare Exposure ${ }^{a}$} \\
\hline Hospital onset ( $\mathrm{HO})$ & 7 & 0.3 & 425 & 0.8 & 2 & 0.2 & 136 & 0.6 \\
\hline Healthcare-associated (HA) & 185 & 7.1 & 3,615 & 7.1 & 73 & 6.4 & 1,240 & 5.8 \\
\hline Community-associated (CA) & 2,399 & 92.7 & 47,376 & 92.7 & 1,057 & 93.4 & 19,950 & 93.9 \\
\hline \multicolumn{9}{|l|}{ Specimen Type } \\
\hline Skin and Soft Tissue Infection (SSTI) & 2,079 & 80.3 & 41,129 & 80.5 & 825 & 72.9 & 15,597 & 73.4 \\
\hline Invasive & 17 & 0.7 & 308 & 0.6 & 6 & 0.5 & 146 & 0.7 \\
\hline Other non-invasive & 446 & 17.2 & 8,837 & 17.3 & 271 & 23.9 & 5,061 & 23.8 \\
\hline Unknown & 47 & 1.8 & 835 & 1.6 & 30 & 2.7 & 440 & 2.1 \\
\hline \multicolumn{9}{|c|}{$\begin{array}{l}\text { A single MRSA isolate can be classified as more than one healthcare- or community-associated exposure, } \\
\text { therefore the counts may be greater than the total N. } \\
\text { Data Source: NMCPHC HL7 formatted microbiology and Standard Inpatient Data Record (SIDR) databases. } \\
\text { Prepared by the EpiData Center Department, Navy and Marine Corps Public Health Center, on } 04 \text { November } \\
2014 .\end{array}$} \\
\hline
\end{tabular}

The annual incidence rates for the first surveillance time period (2005 - 2009) ranged from 360.5 to 479.7, with an overall incidence rate of 424.1 per 100,000 AD service members per year for the DOD. In the DON, the annual incidence rates for the first surveillance time period ranged from 401.2 to 521.4, with an overall incidence rate of 448.4 per 100,000 AD service members per year. During this time period, the incidence rates fluctuated around the historical mean with a generally decreasing trend for both DOD and DON beneficiaries (Figures 5 and 6). Substantial peaks in incidence rate that were outside the natural variation occurred in 2006 for both the DOD and DON. Trends in the second surveillance time period $(2010-2013)$ were quite different from trends in the first time period. In the second time period, the annual incidence rates ranged from 142.6 to 288.0, with an overall incidence rate of 204.6 per 100,000 AD service members per year for the DOD. In the DON, the annual incidence rates for the second surveillance time period ranged from 162.6 to 273.9 , with an overall incidence rate of 205.1 per 100,000 AD service members per year. Overall, incidence decreased for the entire second time period with a $50.5 \%$ decrease in the DOD and a $40.7 \%$ decrease in the DON. Incidence rates in the last two years for this period were below the historic mean and outside the natural variation for expected rates for both the DOD and DON AD populations. Incidence rates in 2013 were the lowest rates documented for both surveillance periods for AD service members in the DOD and DON. 


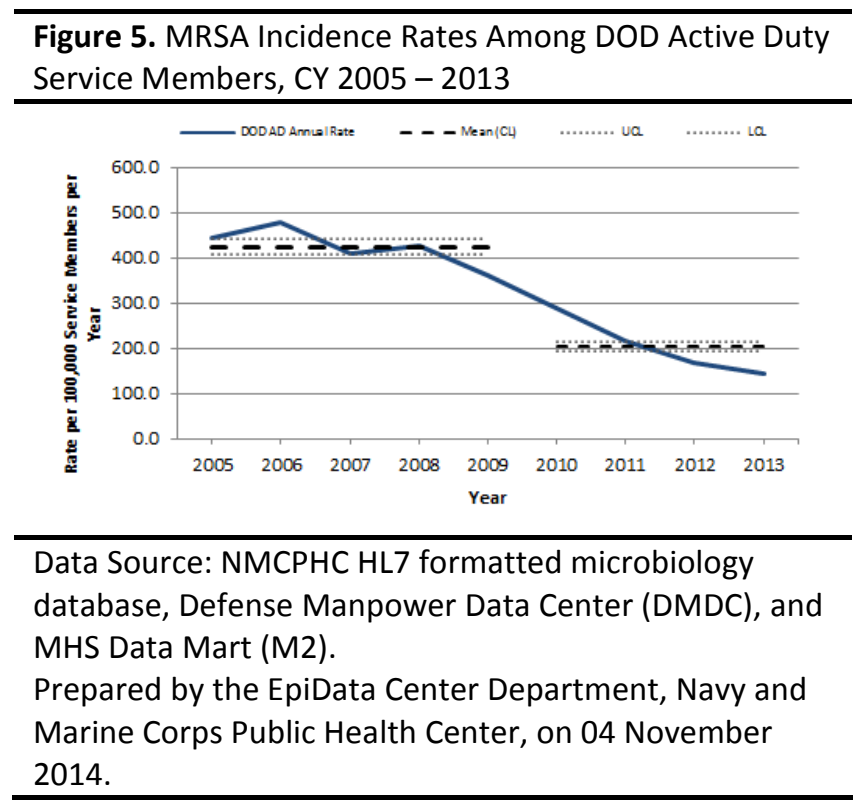

Figure 6. MRSA Incidence Rates Among DON Active Duty Service Members, CY 2005 - 2013

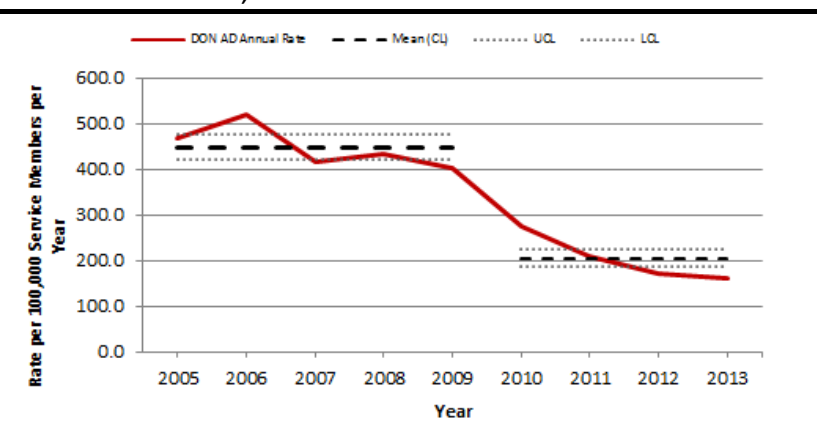

Data Source: NMCPHC HL7 formatted microbiology database, Defense Manpower Data Center (DMDC), and MHS Data Mart (M2).

Prepared by the EpiData Center Department, Navy and Marine Corps Public Health Center, on 04 November 2014.

\section{Recruits - DON}

In 2013, there were 168 unique MRSA infections identified among DON recruits during the recruit training period; $22.8 \%$ of these were Navy recruit cases and $77.3 \%$ were Marine Corps recruit cases. Females, persons aged less than 18 years, and Marine Corps recruits had the highest rates of infection in 2013 (Table 6). The historical data differs here, where males and recruits aged 18 - 24 years had the highest rates of MRSA cases. In 2013 and historically, Marine Corps recruits had approximately four times the rate of MRSA cases than Navy recruits.

\begin{tabular}{|c|c|c|c|c|}
\hline & \multicolumn{2}{|c|}{$2013(N=168)$} & \multicolumn{2}{|c|}{ Historic $(N=3,247)$} \\
\hline & Count & Rate & Count & Rate \\
\hline \multicolumn{5}{|l|}{ Gender } \\
\hline Female & 30 & 234.3 & 319 & 380.0 \\
\hline Male & 138 & 179.6 & 2,928 & 586.1 \\
\hline \multicolumn{5}{|c|}{ Age Group (in Years) } \\
\hline$<18$ & 7 & 293.1 & 97 & 478.0 \\
\hline $18-24$ & 151 & 217.0 & 2,968 & 564.6 \\
\hline $25-34$ & 10 & 206.1 & 180 & 480.5 \\
\hline \multicolumn{5}{|l|}{ Sponsor Service } \\
\hline Navy & 38 & 90.8 & 686 & 230.1 \\
\hline Marine Corps & 130 & 371.8 & 2,561 & 898.7 \\
\hline \multicolumn{5}{|c|}{$\begin{array}{l}\text { Rates are presented as the rate per } 100,000 \text { persons per year } \\
\text { Data Source: NMCPHC HL7 formatted microbiology and } \\
\text { Defense Manpower Data Center (DMDC) databases. } \\
\text { Prepared by the EpiData Center Department, Navy and } \\
\text { Marine Corps Public Health Center, on } 13 \text { November } 2014 .\end{array}$} \\
\hline
\end{tabular}


As has been the historical trend, most infections in 2013 among DON recruits were CA and occurred in the outpatient setting (Table 7). Unlike the historical data, in 2013, DON recruits most often had MRSA infections isolated from SSTIs (54.8\%), with wounds (39\%) as the most commonly identified specimen source, followed by swabs (32\%) and abscesses (23.3\%) (data not shown).

\begin{tabular}{|c|c|c|c|c|}
\hline & \multicolumn{2}{|c|}{$2013(N=168)$} & \multicolumn{2}{|c|}{ Historic $(N=3,247)$} \\
\hline & Count & Percentage & Count & Percentag \\
\hline \multicolumn{5}{|l|}{ Encounter Type } \\
\hline Inpatient & 11 & 6.5 & 95 & 2.9 \\
\hline Outpatient & 157 & 93.5 & 3,152 & 97.1 \\
\hline \multicolumn{5}{|l|}{ Healthcare Exposure ${ }^{a}$} \\
\hline Hospital onset $(\mathrm{HO})$ & 0 & -- & 10 & 0.3 \\
\hline Healthcare-associated (HA) & 0 & -- & 43 & 1.3 \\
\hline Community-associated (CA) & 168 & 100.0 & 3,196 & 98.5 \\
\hline \multicolumn{5}{|l|}{ Specimen Type } \\
\hline Skin and Soft Tissue Infection (SSTI) & 92 & 54.8 & 1,597 & 49.2 \\
\hline Invasive & 1 & 0.6 & 19 & 0.6 \\
\hline Other non-invasive & 75 & 44.6 & 1,618 & 49.8 \\
\hline Unknown & 0 & -- & 13 & 0.4 \\
\hline \multicolumn{5}{|c|}{$\begin{array}{l}{ }^{a} \text { A single MRSA isolate can be classified as more than one } \\
\text { healthcare- or community-associated exposure, therefore the } \\
\text { counts may be greater than the total } \mathrm{N} \text {. }\end{array}$} \\
\hline \multicolumn{5}{|c|}{$\begin{array}{l}\text { Data Source: NMCPHC HL7 formatted microbiology and Defense } \\
\text { Manpower Data Center (DMDC) databases. }\end{array}$} \\
\hline \multicolumn{5}{|c|}{ Prepared by the EpiData Center Department, Navy and Marine } \\
\hline
\end{tabular}

In 2013, 167 DON recruits had an incident MRSA infection occur during the recruit training period, resulting in an incidence rate of 217.4 cases per 100,000 recruits. In 2013, the highest rate of MRSA incidence was identified in Marine Corps recruits at Marine Corps Recruit Depot (MCRD) Parris Island (505.4 cases per 100,000 recruits), followed by MCRD San Diego (206.6 cases per 100,000 recruits), and Naval Training Center (NTC) Great Lakes (90.8 cases per 100,000 recruits) (Figure 7). Since 2005, incidence rates by year at MCRD Parris Island were approximately two and a half times higher than rates at MCRD San Diego, and approximately five times higher than rates at NTC Great Lakes. Incidence rates in the DON recruit population have consistently decreased since 2005, with the 2013 incidence rates observed as the lowest since 2005 at all three training locations. From 2005 to 2013, incidence rates decreased by 71.6\% at MCRD Parris Island, 58\% at MCRD San Diego, and 60\% at NTC Great Lakes. 


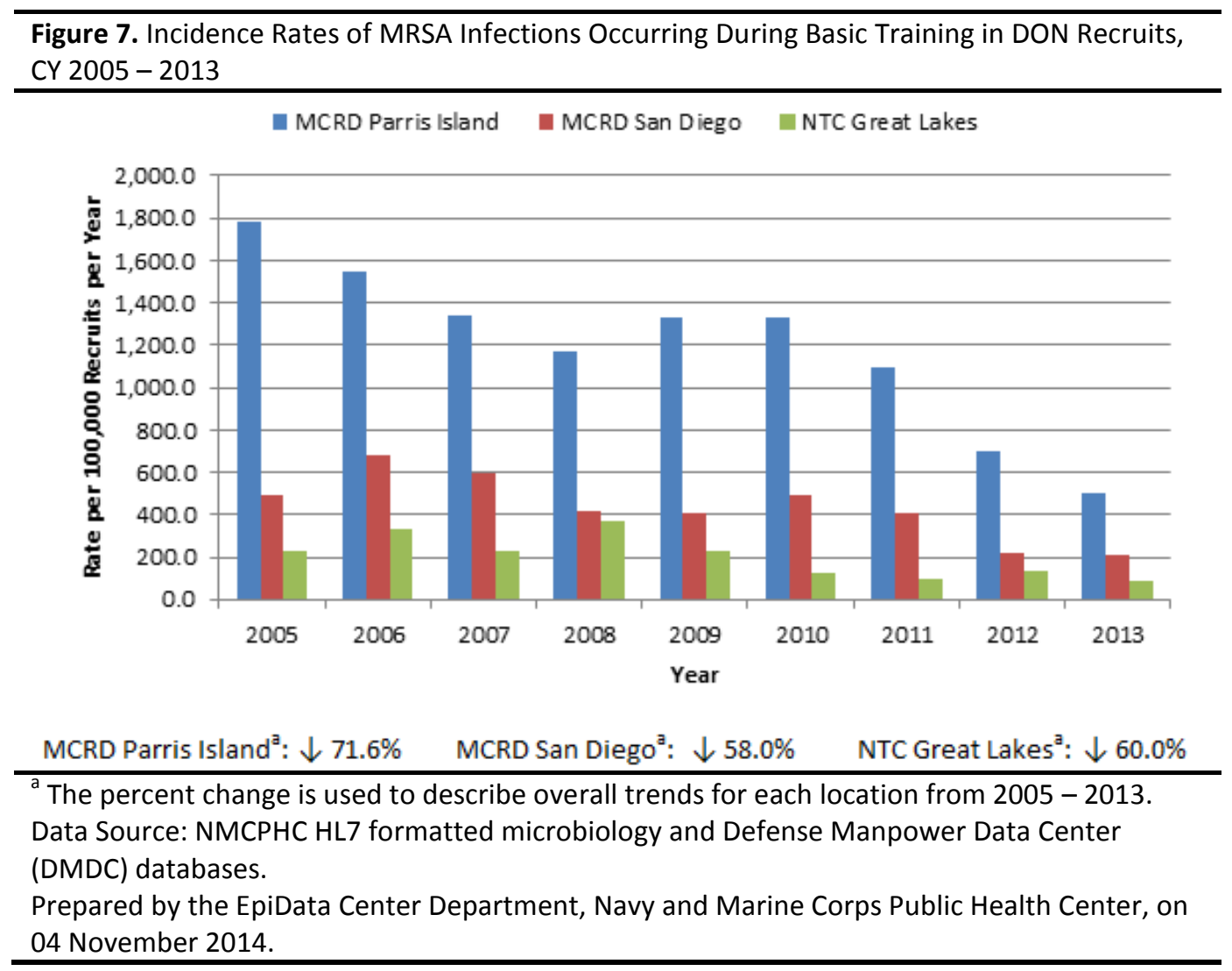

Both Navy and Marine Corps recruits exhibit variation in infection rates throughout the training period. The early weeks of recruit training (the first four weeks for Marine Corps recruits and the first three weeks for Navy recruits) had the lowest proportion (21.1\%) of infections; the highest proportion (40.8\%) of infections occurred during the middle weeks of recruit training (weeks five through nine for Marine Corps recruits and weeks four through six for Navy recruits). The last four weeks of training for each service represented $38.1 \%$ of the recruit infections during training (Figure 8). On average, the length of time to infection was 52 days (eight weeks) into training for Marine Corps recruits and 38 days (six weeks) into training for Navy recruits; these points are just beyond the midpoint of the recruit training period for both services. 


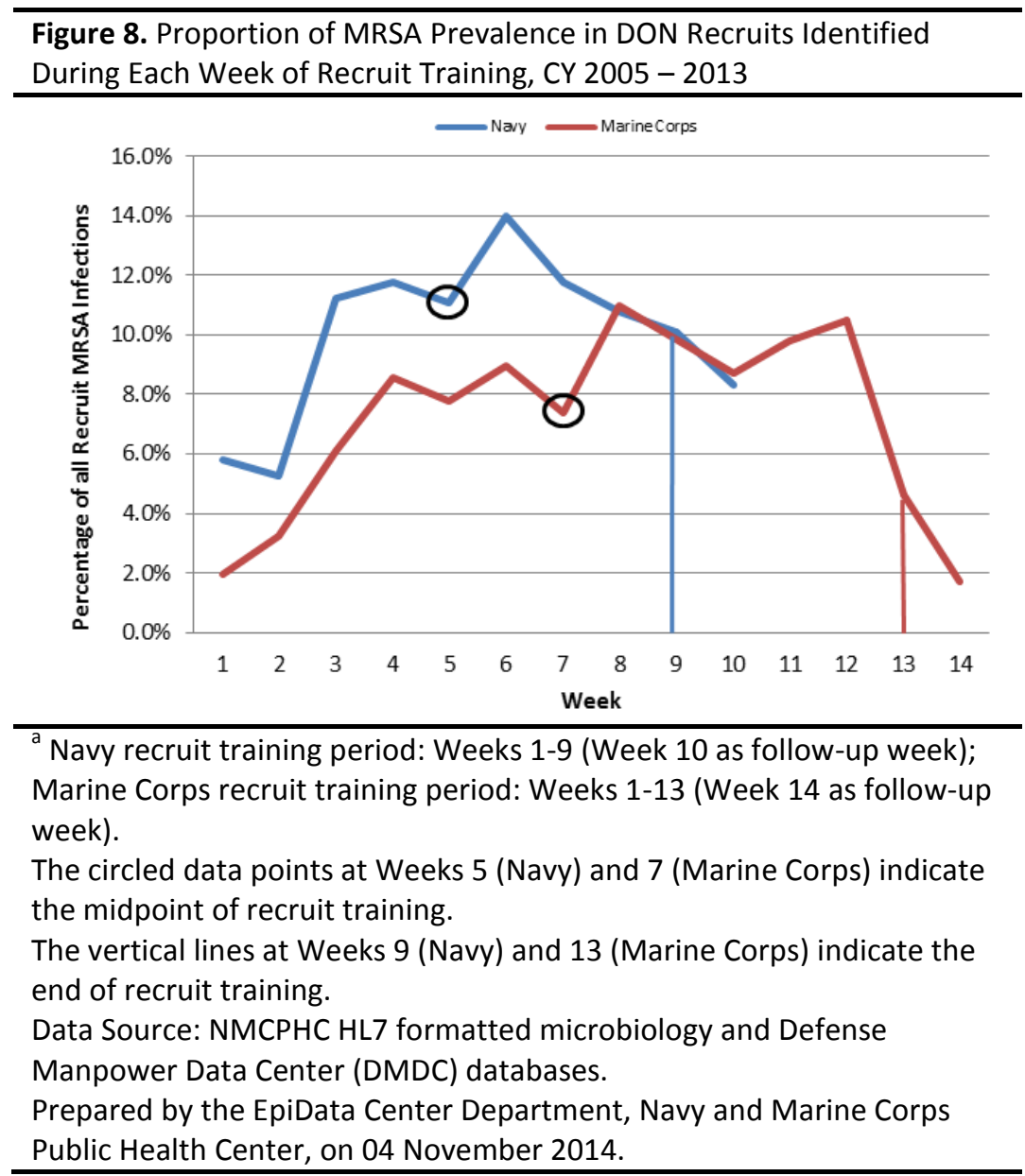

\section{Antibiotics}

\section{Prescription Practices}

Among DOD and DON beneficiaries prescribed an oral antibiotic, the most commonly prescribed outpatient oral antibiotics $(\mathrm{N}=2,992 ; \mathrm{N}=1,183$, respectively) for MRSA infections in 2013 were trimethoprim/sulfamethoxazole, clindamycin, and doxycycline. The most commonly prescribed inpatient oral antibiotics ( $\mathrm{N}=506 ; \mathrm{N}=236$, respectively) in 2013 for the DOD and DON were clindamycin, vancomycin, and trimethoprim/sulfamethoxazole. For both the DOD and DON in 2013, among intravenous antibiotics ( $\mathrm{N}=812 ; \mathrm{N}=334$, respectively), regardless of encounter setting, vancomycin was most commonly prescribed, followed by clindamycin (Table 8). The historical trend of antibiotic prescriptions for $2006-2012$ shows similar patterns of prescription use. 
MRSA Infections in the DOD: Annual Report 2013

NCMPHC-EDC-TR-44-2015

Prepared: December 2014

EpiData Center Department

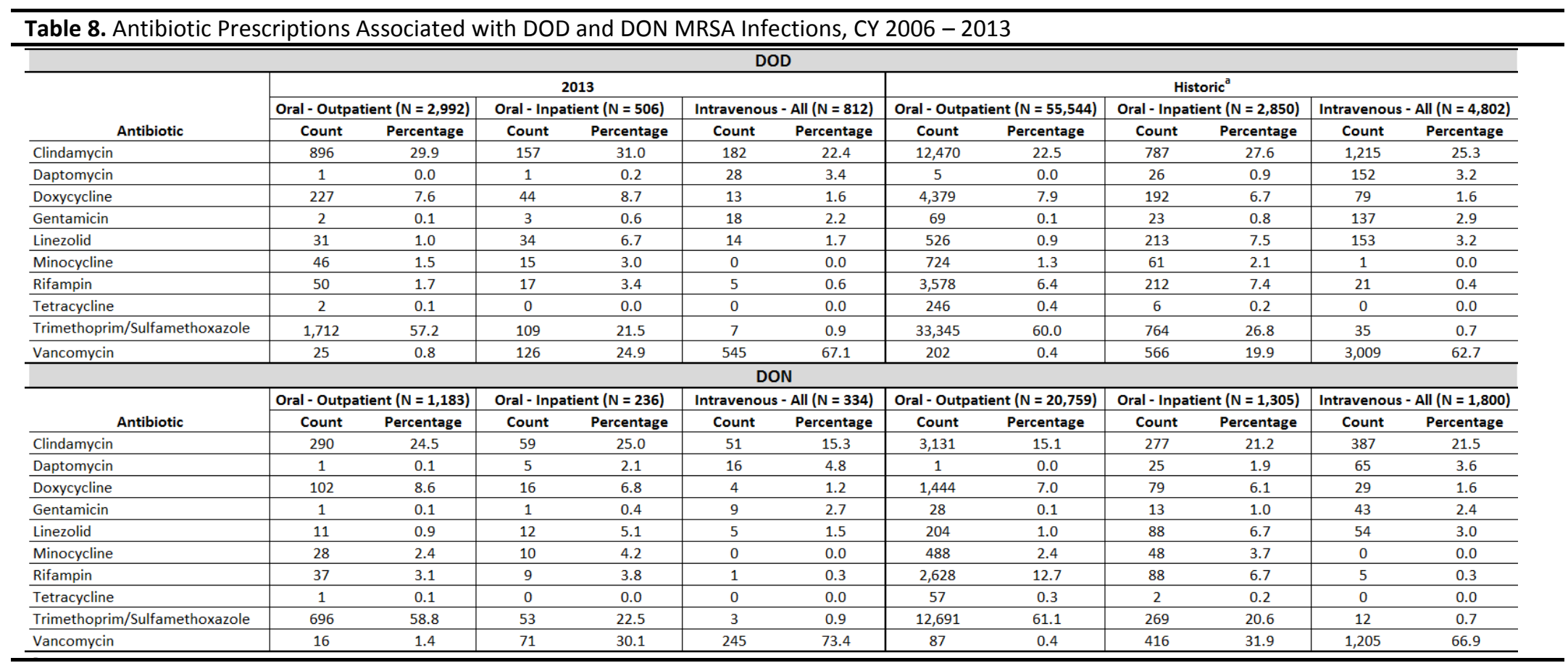

${ }^{a}$ Outpatient pharmacy data are available from 2006 forward. Inpatient and intravenous pharmacy data are available from July 2009 forward.

Data Source: NMCPHC HL7 formatted microbiology and HL7 pharmacy databases.

Prepared by the EpiData Center Department, Navy and Marine Corps Public Health Center, on 11 December 2014.

\section{Susceptibilities}

Tables 9 and 10 summarize annual antibiotic susceptibilities for the DOD and DON population for 2005 - 2013. On average from 2005 - 2013 in the DOD, MRSA isolates were more than 95\% susceptible to gentamicin, linezolid, rifampin, tetracycline, trimethoprim/sulfamethoxazole, and vancomycin; in the DON, MRSA isolates were more than 95\% susceptible to linezolid, 
rifampin, tetracycline, trimethoprim/sulfamethoxazole, and vancomycin. On average, isolates were less than $2 \%$ susceptible to amoxicillin/clavulanate and cefazolin in both the DOD and DON, and to ceftriaxone and imipenem for only the DOD. Prior to 2010, doxycycline susceptibility was not tested within the DOD or DON; however, since 2010, MRSA isolates were more than $97 \%$ susceptible to doxycycline in both the DOD and DON. In the DOD from $2005-$ 2013, cefazolin showed a significant $(P=<.001)$ trend and decrease in susceptibility since 2005. Conversely, a significant $(P<.001)$ trend in susceptibility emerged for erythromycin and cefotaxime in both the DOD and the DON, and for gentamicin in the DON; these antibiotics showed an increase in susceptibility from 2005 - 2013. In the DOD, a significant susceptibility trend was observed for clindamycin $(P<.001)$, doxycycline $(P=.03)$, gentamicin $(P<.001)$, rifampin $(P=.001)$, tetracycline $(P<.001)$, and vancomycin $(P<.001)$ from $2005-2013$ (Table $9)$; these antibiotics showed a stable pattern of susceptibility during the time period. For the DON, a significant trend was observed for ceftriaxone $(P=.01)$, imipenem $(P<.001)$, rifampin $(P<.001)$, tetracycline $(P<.001)$, trimethoprim/sulfamethoxazole $(P=.02)$, and vancomycin $(P$ $<.001)$ (Table 10); these antibiotics showed a stable pattern of susceptibility during the time period.

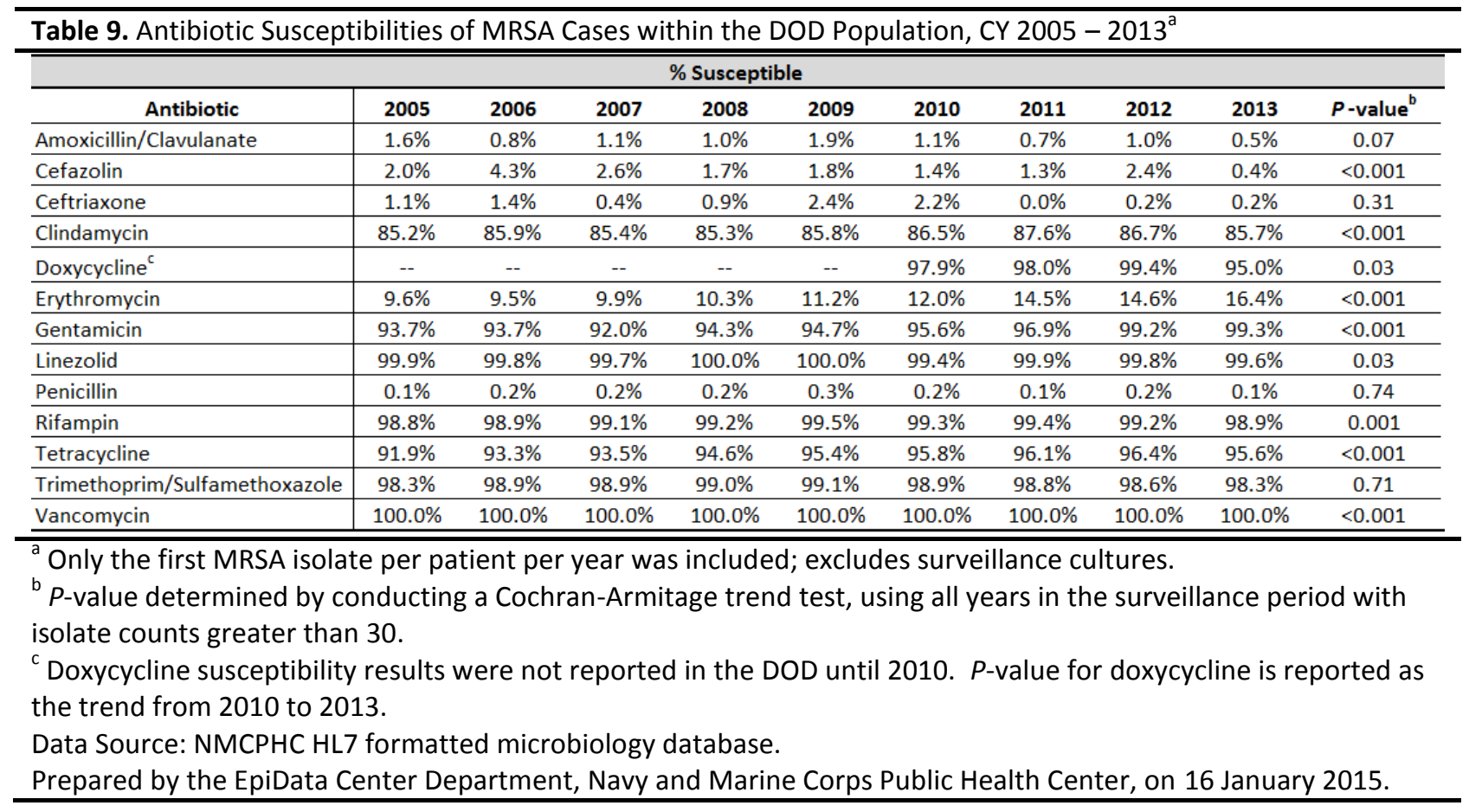


MRSA Infections in the DOD: Annual Report 2013

NCMPHC-EDC-TR-44-2015

Prepared: December 2014

EpiData Center Department

\begin{tabular}{|c|c|c|c|c|c|c|c|c|c|c|}
\hline \multicolumn{11}{|c|}{ \% Susceptible } \\
\hline Antibiotic & 2005 & 2006 & 2007 & 2008 & 2009 & 2010 & 2011 & 2012 & 2013 & $P$-value ${ }^{\text {b }}$ \\
\hline Amoxicillin/Clavulanate & $0.5 \%$ & $0.8 \%$ & $0.4 \%$ & $1.0 \%$ & $4.9 \%$ & $2.0 \%$ & $0.3 \%$ & $0.5 \%$ & $0.5 \%$ & 0.05 \\
\hline Cefazolin & $0.8 \%$ & $2.5 \%$ & $0.7 \%$ & $1.1 \%$ & $2.9 \%$ & $1.5 \%$ & $1.0 \%$ & $2.4 \%$ & $0.7 \%$ & 0.32 \\
\hline Ceftriaxone & $0.4 \%$ & $1.4 \%$ & $0.3 \%$ & $1.7 \%$ & $19.6 \%$ & $13.5 \%$ & $0.0 \%$ & $0.0 \%$ & $0.0 \%$ & 0.01 \\
\hline Clindamycin & $87.0 \%$ & $85.8 \%$ & $83.5 \%$ & $83.3 \%$ & $85.1 \%$ & $84.4 \%$ & $87.8 \%$ & $86.2 \%$ & $87.3 \%$ & 0.07 \\
\hline Doxycycline $^{c}$ & -- & -- & -- & -- & -- & $95.2 \%$ & $100.0 \%$ & $100.0 \%$ & $96.0 \%$ & 0.26 \\
\hline Erythromycin & $9.5 \%$ & $9.8 \%$ & $11.1 \%$ & $10.4 \%$ & $12.3 \%$ & $12.4 \%$ & $16.2 \%$ & $15.8 \%$ & $16.2 \%$ & $<0.001$ \\
\hline Gentamicin & $89.3 \%$ & $89.3 \%$ & $87.2 \%$ & $91.1 \%$ & $90.9 \%$ & $91.6 \%$ & $94.4 \%$ & $98.8 \%$ & $99.5 \%$ & $<0.001$ \\
\hline Linezolid & $99.9 \%$ & $99.7 \%$ & $99.5 \%$ & $100.0 \%$ & $100.0 \%$ & $99.1 \%$ & $99.9 \%$ & $99.8 \%$ & $99.3 \%$ & 0.11 \\
\hline Penicillin & $0.2 \%$ & $0.2 \%$ & $0.1 \%$ & $0.2 \%$ & $0.2 \%$ & $0.0 \%$ & $0.1 \%$ & $0.2 \%$ & $0.1 \%$ & 0.84 \\
\hline Rifampin & $98.5 \%$ & $98.4 \%$ & $98.9 \%$ & $99.0 \%$ & $99.2 \%$ & $99.2 \%$ & $99.5 \%$ & $99.3 \%$ & $99.2 \%$ & $<0.001$ \\
\hline Tetracycline & $92.5 \%$ & $94.4 \%$ & $94.8 \%$ & $95.6 \%$ & $96.8 \%$ & $96.4 \%$ & $96.2 \%$ & $96.4 \%$ & $95.8 \%$ & $<0.001$ \\
\hline Trimethoprim/Sulfamethoxazole & $98.8 \%$ & $98.7 \%$ & $99.1 \%$ & $99.1 \%$ & $98.8 \%$ & $98.9 \%$ & $99.0 \%$ & $97.9 \%$ & $98.4 \%$ & 0.02 \\
\hline Vancomycin & $100.0 \%$ & $100.0 \%$ & $100.0 \%$ & $100.0 \%$ & $100.0 \%$ & $100.0 \%$ & $100.0 \%$ & $100.0 \%$ & $100.0 \%$ & $<0.001$ \\
\hline $\begin{array}{l}\text { a Only the first MRSA isolat } \\
\text { b } P \text {-value determined by co } \\
\text { isolate counts greater than } \\
{ }^{c} \text { Doxycycline susceptibility } \\
\text { the trend from } 2010 \text { to } 201 \\
\text { Data Source: NMCPHC HL7 } \\
\text { Prepared by the EpiData Ce }\end{array}$ & $\begin{array}{l}\text { e per pa } \\
\text { nducting } \\
30 \text {. } \\
\text { results } \\
3 . \\
\text { formatt } \\
\text { nter De }\end{array}$ & $\begin{array}{l}\text { ent per } \\
\text { a Cochra } \\
\text { ere not } \\
\text { d microl } \\
\text { artment }\end{array}$ & $\begin{array}{l}\text { ear was } \\
\text { n-Armit } \\
\text { eported } \\
\text { iology d } \\
\text { Navy ar }\end{array}$ & $\begin{array}{l}\text { included } \\
\text { ge trenc } \\
\text { in the D } \\
\text { tabase. } \\
\text { d Marin }\end{array}$ & $\begin{array}{l}\text { exclud } \\
\text { test, us } \\
\text { D until }\end{array}$ & $\begin{array}{l}\text { survei } \\
\text { o10. } P \text { - }\end{array}$ & $\begin{array}{l}\text { ance cu } \\
\text { rs in the } \\
\text { alue for }\end{array}$ & $\begin{array}{l}\text { ures. } \\
\text { surveilla } \\
\text { doxycyc }\end{array}$ & $\begin{array}{l}\text { nce peri } \\
\text { ne is re }\end{array}$ & $\begin{array}{l}\text { d with } \\
\text { orted as }\end{array}$ \\
\hline
\end{tabular}

In 2013, $14 \%$ of DOD ( $N=5,871)$ and $13 \%$ of DON $(\mathrm{N}=2,228)$ MRSA cases were resistant to both erythromycin and clindamycin (inducible clindamycin resistance). In comparison to historical data, in the DOD, 2013 had the highest percentage of cases with inducible clindamycin resistance, whereas the DON had a slightly lower percentage of cases in 2013 compared to its peak in 2012 (Figure 9). Overall, the percentage of MRSA cases with inducible clindamycin resistance has increased over time, with a statistically significant trend from $2005-2013(P<$ 0.0001) for both the DOD and DON. Among the MRSA cases with inducible clindamycin resistance in 2013, just over $75 \%$ were identified in the outpatient setting for both the DOD and DON, and approximately $60 \%$ were CA infections for both populations. 
MRSA Infections in the DOD: Annual Report 2013

NCMPHC-EDC-TR-44-2015

Prepared: December 2014

EpiData Center Department

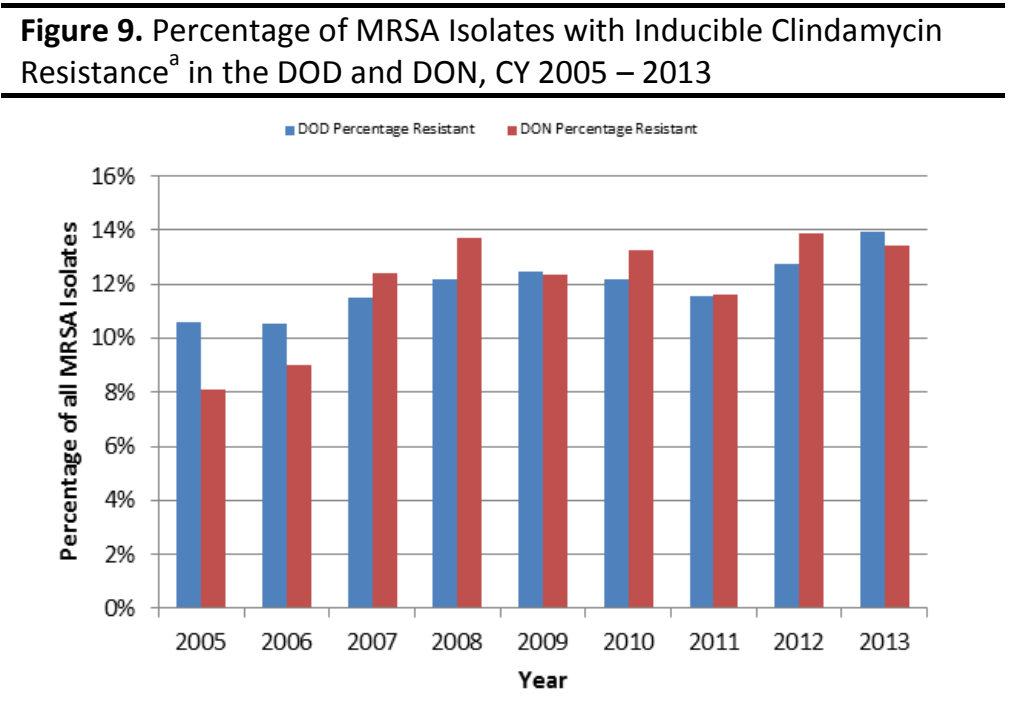

\footnotetext{
${ }^{a}$ Isolate must be resistant to both erythromycin and clindamycin to meet criteria for inducible clindamycin resistance.

Data Source: NMCPHC HL7 formatted microbiology database.

Prepared by the EpiData Center Department, Navy and Marine

Corps Public Health Center, on 26 June 2014.
} 


\section{Discussion}

MRSA incidence rates in the general US population have been declining in recent years; this decrease continued in 2013. ${ }^{14}$ Overall, the MRSA incidence rates in the DOD and DON surveillance populations also declined in 2013, maintaining the descending trend observed since 2005. The AD DOD and DON populations experienced a decline in incidence rates from $2005-$ 2013 as well, with rates in 2013 the lowest since MHS-wide surveillance began. Additionally, the overall trend of MRSA incidence also decreased for DON recruits across all training facilities from 2005 - 2013. These decreasing trends, along with other indicators in this report, suggest that increased awareness, greater adherence to infection control and prevention strategies, and improved antimicrobial stewardship practices are proving effective in both the civilian and military healthcare communities.

Although overall MRSA incidence rates are declining, it is important to remain vigilant due to its changing epidemiology. ${ }^{16,39}$ Historically, MRSA was most often seen in the hospital setting, predominately affecting those with established risk factors (i.e., hospitalized, elderly, or immunocompromised individuals). However, recent literature shows that CA MRSA has disproportionately affected groups without typical risk factors, such as children or young adults. ${ }^{11,17,18}$ Within the DOD and DON, the majority of MRSA cases in 2013 were classified as CA $(84.4 \%)$. Further analysis revealed that more than three-fourths of these CA MRSA cases represented individuals under the age of 34. Overall, CA MRSA cases within the DOD and DON follow typical patterns generally observed in the US for CA MRSA. The shift to predominately CA MRSA infections is likely multi-faceted, but may be to some extent attributed to the misuse of antibiotics and the absence of infection control interventions in the community. However, this shift is not likely due to surveillance screening programs in use within the MHS, as these types of surveillance samples have been excluded from this analysis. Interventions that support antimicrobial stewardship and infection control are more easily implemented and enforced in the healthcare setting than the community setting, which could potentially contribute to a reservoir of CA MRSA in the community.

Throughout the surveillance time period, Marine Corps beneficiaries, including AD service members, have consistently maintained the highest incidence rates of MRSA compared to the other DOD services. While this analysis is not able to describe this trend further, Marine Corps beneficiaries account for the smallest population among DOD services and are therefore subject to bias due to the size of the population and fluctuations in case counts. A separate, more thorough analysis may provide further insight into the Marine Corps beneficiary population. However, this analysis identified that trends of MRSA incidence among Marine Corps beneficiaries show a clear and consistently decreasing disease burden.

Seasonality is another important factor in rates of MRSA infection and research has demonstrated that seasonal variations exist. ${ }^{20,23,24}$ Also, regional differences in MRSA infections exist due to climatic conditions; geographic locations with warmer temperatures generally report higher rates of MRSA. Infections tend to peak during the summer and fall months in climatic regions that are temperate or tropical. ${ }^{20}$ Within the MHS, the highest incidence rates occurred 
between the months of July and September and generally aligned with the normal variability of typical geographical and seasonal patterns.

Given the seasonal and geographic variability of MRSA infections, it was not surprising that differences in MRSA incidence rates emerged for DON recruits training in different geographic locations. The incidence rate was highest at MCRD Parris Island in South Carolina, which is located in a hotter, more humid climate than the other training depots. The Parris Island rate contrasts with lower rates at MCRD San Diego, which is located in a hotter but drier climate in Southern California, and at NTC Great Lakes, which is located in a colder, yet wetter climate in Illinois. ${ }^{40}$ MCRD Parris Island consistently reported the highest incidence of MRSA compared to the other recruit training centers from 2005 - 2013. However, MCRD Parris Island also showed the largest decrease in incidence, with a $71.6 \%$ reduction in cases since 2005 . This is likely attributed to the vigorous screening and MRSA surveillance programs in place at MCRD Parris Island that have been used to track infection and respond to changes in disease incidence quickly. This type of close monitoring and focused interventions are important across all training environments to ensure the health of recruits and to minimize outbreaks that may occur due to close living conditions and the physical requirements specific to recruit training.

In addition, some military-specific settings and occupations present unique risk factors for the development of MRSA infections. A study conducted among military recruits showed that exposure to the military recruit training environment (a close contact environment with intense physical activity) increases the risk for MRSA infection. ${ }^{32}$ As such, the length of time spent in the training environment potentially increases exposures and the risk for infection. Length of training time differs by service for DON recruits; Marine Corps recruits participate in training for 13 weeks, while Navy recruits participate in training for 9 weeks. This analysis found that Marine Corps recruits had nearly four times the rate of MRSA infection as Navy recruits. Marine Corps recruits spend four more weeks in training than their Navy counterparts, thus increasing their exposure and potentially increasing their risk for infection and ultimately their infection rates. Additionally, a report concerning a MRSA outbreak among Marine Corps recruits noted that $86 \%$ of infections related to the outbreak occurred in the later weeks of training. ${ }^{32}$ In this analysis, nearly $40 \%$ of MRSA infections were identified in the last four weeks of training for each service. Recruits may delay care in an effort to complete training, leading to increased rates of infection in later weeks. Given the risk for increased MRSA infection among recruits due to the nature of the recruit environment and inherent reservoirs of infection contained within that environment, provision of MRSA screenings, targeted interventions, and careful monitoring of known and suspected reservoirs in the environment could minimize rates of infection in this population throughout the recruit training period.

Susceptibility patterns of MRSA isolates dictate effective treatment options. During the $2005-$ 2013 surveillance period, susceptibility of MRSA remained stable in the DOD with over 95\% susceptibility for doxycycline, gentamicin, rifampin, tetracycline, trimethoprim/sulfamethoxazole, and vancomycin. Similar patterns were seen within the DON during the same period, with greater than 95\% susceptibility for rifampin, tetracycline, trimethoprim/sulfamethoxazole, and vancomycin. MRSA isolates also showed increasing susceptibility to erythromycin in both the DOD and the DON, and also to gentamicin in the 
DON. Only cefazolin in the DOD displayed any decrease in susceptibility. These findings suggest that there have been limited changes to the resistance patterns seen among MRSA within the MHS and that, in general, those antibiotics recommended for treatment of MRSA remain as viable treatment options.

Clindamycin is one of the most recommended antibiotics for MRSA treatment per the IDSA guidelines. ${ }^{37}$ Studies show that susceptibility patterns differ between the inpatient and outpatient settings and sites of infection, ${ }^{41}$ thus treatment practices for MRSA may vary slightly depending on these factors. This analysis showed that clindamycin susceptibility differed drastically between healthcare settings, with lower susceptibility (average 59.5\%) in the inpatient setting and higher susceptibility (average 88\%) in the outpatient setting from 2005 - 2013. Additionally, for both the inpatient and outpatient settings, the majority of the isolates were from sites indicative of SSTIs (primarily wounds or abscesses). These findings suggest that clindamycin alone may not be the most viable option for MRSA SSTIs in the inpatient setting for DOD beneficiaries. It is important to monitor clindamycin prescription practices and changes in susceptibility that would affect treatment choices.

Since the early 2000s, experts have also documented another concern on the use of clindamycin: inducible clindamycin resistance. This type of resistance occurs when organisms have the genetic potential to become resistant to clindamycin during the course of treatment, thereby causing treatment failures and enhancing the virulence of the MRSA pathogen. ${ }^{29}$ Within the MHS in 2013, MRSA isolates identified with inducible resistance to clindamycin were the highest since surveillance began at $14 \%$ in the DOD and $13.4 \%$ in the DON. Although the percentage of inducible clindamycin resistance has increased each year since 2005, the proportion remains below that seen in the general US population (range $18-52 \%)^{27,29,42,43}$ Close monitoring of clindamycin susceptibility patterns of MRSA is needed to ensure optimal disease prevention and treatment measures.

This annual report summarized MRSA incidence and prevalence in the DOD and DON beneficiary populations in 2013 and reported changes from previously identified trends. Given the possible change in MRSA's epidemiology, the shifting viability of treatment options, and MRSA's association with military recruits, it is important to monitor and manage the risk to the DOD population at large. Continued surveillance is warranted to monitor any changes in burden, susceptibility, and treatment options and to guide targeted prevention efforts. 


\section{Limitations}

HL7 formatted data are generated within the CHCS at fixed MTFs; therefore, this analysis does not include microbiology records from purchased care providers, shipboard facilities, battalion aid stations, or in-theater facilities. Microbiology testing results only list the organism(s) that were identified and do not provide information on the organisms the physician may have originally suspected or for what the test was intended.

Microbiology data are useful for identifying laboratory confirmed cases of illness. However, cases where a physician chooses to treat presumptively without laboratory confirmation will not be captured. Clinical practice with regards to culturing varies between providers and facilities. Examples of situations where cultures may not be performed include confirmatory tests for patients with influenza-like illness symptoms, or patients with superficial infections who are treated presumptively. Therefore, isolate counts identified here may be an underestimate of the actual burden of MRSA in the DOD and DON.

The data restructuring process does not capture non-standard CHCS records. These nonstandard records may include those containing the results of tests performed at reference laboratories or novel organism antibiotic combinations. Additionally, not all results of rapid screening tests, such as polymerase chain reaction (PCR) methods, are consistently captured. The use of microbiology data for analysis of antibiotic resistance is limited by the practice of cascade reporting, in which antibiotic sensitivity results are conditionally reported to CHCS to guide treatment decisions. Cascade reporting is practiced to varying degrees at DOD MTFs. Because the EDC uses interpreted values for resistant, intermediate, and susceptible classifications, this report may over- or under-report MRSA. Specific information on the type of testing conducted is not necessarily available and it is assumed that records identified with erythromycin and clindamycin resistance were tested appropriately using the D-test to confirm genetic mutations specific to this type of resistance that causes clindamycin treatment failure for MRSA.

A SIDR is created at discharge or transfer from an inpatient MTF. For AD and recruit service members, a SIDR is created on discharge from a military MTF or non-military purchased care facility. For all other beneficiaries, a SIDR is created on discharge from an MTF. Discharge from an inpatient theater or shipboard medical treatment facility does not generate a SIDR and those data were not captured for this analysis. Additionally, the SIDR data feed is provided once a month and some SIDRs may not be received by the EDC up to 30 days after discharge. Data for medical surveillance are considered provisional and medical case counts may change if the discharge record is edited after the patient is discharged.

As the EDC does not receive data based on all DOD beneficiary healthcare encounters (e.g., purchased care in the community), it cannot be determined if an individual truly had no healthcare contact or other risk factors for MRSA infection, or if the individual had a risk factor that was not visible in the available data. Data on other factors (e.g., presence of an invasive device, history of dialysis or surgery, a long-term care facility stay in the 12 months preceding 
the culture) commonly used to define HA infections were not available. Therefore, there may be HA infections currently miscategorized as CA infections. Without the ability to identify these other HA infections, a more accurate estimate of CA infections could not be determined. Given the relatively healthy military population, however, any misclassification bias is likely minimal.

The pharmacy databases consist of outpatient non-intravenous prescriptions (outpatient), inpatient non-intravenous prescriptions (unit dose), and intravenous prescriptions (intravenous). Though treatment compliance in the inpatient setting can be assumed, outpatient pharmacy records indicate that a patient received a prescription and subsequent compliance is unknown. Due to near real-time data feeds, analysts are able to determine if a prescription was edited or canceled; however, the time difference between these events may allow for a short period of treatment not considered in this analysis. During ongoing surveillance efforts, patient treatment status may change as edited or canceled prescription records are received.

Outpatient pharmacy data are available beginning in 2006, while unit dose and intravenous data are available from July 2009 forward. Analysis of prescription practices and pre- and postculture antibiotic use are limited due to data availability. Therefore, trends of prescription use should be interpreted cautiously using these parameters.

It is possible that not all antibiotic prescriptions were dispensed in response to a MRSA infection. Antibiotics that were prescribed within the appropriate timeframe to be associated with a MRSA specimen collection date may have actually been provided for reasons other than the MRSA infection, such as a different infection occurring after MRSA was isolated. However, most antibiotics identified as being associated with a MRSA infection were antibiotics that are typically used to treat MRSA, so it is likely that the majority of prescriptions in this analysis were truly in response to the MRSA infection. 


\section{References}

1. Crum NF, Lee RU, Thornton SA, et al. Fifteen-year study of the changing epidemiology of methicillin-resistant Staphylococcus aureus. Am J Med 2006;119:943-951.

2. Diekema DJ, Pfaller MA, Schnitz FJ, et al. Survey of infections due to Staphylococcus species: frequency of occurrence and antimicrobial susceptibility of isolates collected in the United States, Canada, Latin America, Europe and the Western Pacific Region for the SENTRY Antimicrobial Surveillance Program, 1997-1999. Clin Infect Dis 2001;32(Suppl 2):S114-S132.

3. Kallen AJ, Mu Y, Bulens S, et al. Health care-associated invasive MRSA infections, 20052008. JAMA 2010;304(6):641-648.

4. Klevens RM, Morrison MA, Nadle J, et al. Invasive methicillin-resistant Staphylococcus aureus infections in the United States. JAMA 2007;298(15):1763-1771.

5. Styers D, Sheehan DJ, Hogan P, Sahm DF. Laboratory-based surveillance of current antimicrobial resistance patterns and trends among Staphylococcus aureus strains. Clin Infect Dis 2008;46:S360-S367.

6. Zeller JL, Burke AE, Glass RM. MRSA infections. JAMA 2007;298(15):1826.

7. Ellis MW, Hospenthal DR, Dooley DP, et al. Natural history of community-acquired methicillin-resistant Staphylococcus aureus colonization and infection in soldiers. Clin Infect Dis 2004;39:971-979.

8. Centers for Disease Control and Prevention. CDC - MRSA symptoms. 2010. http://www.cdc.gov/mrsa/symptoms/index.html.

9. Lowy FD. Staphylococcus aureus infections. N Engl J Med 1998;339(8):520-532.

10. Huang SS, Septimus E, Kleinman K, et al. Targeted versus universal decolonization to prevent ICU infection. N Engl J Med 2013. Downloaded from nejm.org at USUHS LRLC UNIFORMED SVCS UNIV on June 6, 2013.

11. Gordon RJ, Lowy FD. Pathogenesis of methicillin-resistant Staphylococcus aureus infection. Clin Infect Dis 2008;46:S350-S359.

12. Centers for Disease Control and Prevention. 2006. Multi-drug resistant organism \& Clostridium difficile-associated disease (MDRO/CDAD module). http://www.cdc.gov/nhsn/PDFs/pscManual/12pscMDRO_CDADcurrent.pdf.

13. Centers for Disease Control and Prevention. 2010. Methicillin-Resistant Staphylococcus aureus (MRSA) Infections. http://www.cdc.gov/hai/pdfs/toolkits/MRSA_toolkit_white_020910_v2.pdf 
14. Centers for Disease Control and Prevention. 2012. Active Bacterial Core surveillance report, Emerging Infections Program Network, methicillin-resistant Staphylococcus aureus, 2012. http://www.cdc.gov/abcs/reports-findings/survreports/mrsa12.html.

15. Centers for Disease Control and Prevention. 2005. Active Bacterial Core surveillance report, Emerging Infections Program Network, methicillin-resistant Staphylococcus aureus, 2005. http://www.cdc.gov/abcs/reports-findings/survreports/mrsa05.html.

16. Boucher HW, Corey GR. Epidemiology of methicillin-resistant Staphylococcus aureus. Clin Infect Dis 2008;46:S344-S349.

17. Centers for Disease Control and Prevention. 2013. General Information about MRSA in the Community. http://www.cdc.gov/mrsa/community/index.html\#q2.

18. Naimi TS, LeDell KH, Como-Sabetti K, et al. Comparison of community- and health careassociated methicillin-resistant Staphylococcus aureus infection. JAMA 2003;290(22):297684.

19. Moran GJ, Krishnadasan A, Gorwitz RJ, et al. Methicillin-resistant $S$. aureus infections among patients in the emergency department. N Engl J Med 2006;355(7):666-674.

20. Mermel LA, Machan JT, Parenteau S. Seasonality of MRSA infections. PLoS One. 2011;6(3):e17925.

21. Van De Griend P, Herwaldt LA, Alvis B, et al. Community-associated methicillin-resistant Staphylococcus aureus, Iowa, USA. Emerg Infect Dis. 2009;15:1582-1589.

22. Szczesiul JM, Shermock KM, Murtaza UI, Siberry GK. No decrease in clindamycin susceptibility despite increased use of clindamycin for pediatric community-associated methicillin-resistant Staphylococcus aureus skin infections. Pediatr Infect Dis J. 2007;26:852-854.

23. Loffeld A, Davies P, Lewist A, Moss C. Seasonal occurrence of impetigo: a retrospective 8year review (1996-2003). Clin Exp Dermatol. 2005;30:512-514.

24. Perencevich EN, McGregor JC, Shardell M, et al. Summer peaks in the incidences of gramnegative bacterial infection - among hospitalized patients. Infect Control Hosp Epidemiol. 2008;29:1124 - 1131 .

25. Centers for Disease Control. CDC - MRSA treatment. 2010. http://blogs.cdc.gov/safehealthcare/2011/03/18/new-clinical-guidelines-for-mrsa-treatment/.

26. Liu C, Bayer A, Cosgrove SE, et al. Clinical practice guidelines by the Infectious Diseases Society of America for the treatment of methicillin-resistant Staphylococcus aureus infectious in adults and children. Clin Infect Dis 2011;52:1-38.

27. Lewis JS II, Jorgensen JH. Inducible clindamycin resistance in Staphylococci: should clinicians and microbiologists be concerned? Clin Infect Dis 2005;40:280-5. 
28. Mallick SK, Basak S, Bose S. Inducible clindamycin resistance in Staphylococcus aureus-a therapeutic challenge. Journal of Clinical and Diagnostic Research 2009;3:1513-1518.

29. Patel M, Waites KB, Moser SA, et al. Prevalence of inducible clindamycin resistance among community- and hospital-associated Staphylococcus aureus isolates. J Clin Microbiol 2006;44(7):2481.

30. National Committee for Clinical Laboratory Standards. Performance standards for antimicrobial susceptibility testing; $14^{\text {th }}$ information supplement. M100-S14. Wayne, PA: NCCLS 2004.

31. Appelbaum PC. Microbiology of antibiotic resistance in Staphylococcus aureus. Clin Infect Dis 2007;45 (Supplement 3):S165-S170.

32. Zinderman CE, Conner B, Malakooti MA, et al. Community-acquired methicillin-resistant Staphylococcus aureus among military recruits. Emerg Infect Dis 2004;10(5):941-944.

33. Leamer NK, Clemmons NS, Jordan NN, Pacha LA. Update: Community-acquired methicillin-resistant Staphylococcus aureus skin and soft tissue infection surveillance among active duty military personnel at Fort Benning GA, 2008-2010. Mil Med 2013;178(8):914-20.

34. Landrum MI, Neumann C, Cook C, et al. Epidemiology of Staphylococcus aureus blood and skin and soft tissue infections in the US military health system, 2005-2010. JAMA 2012;308(1).

35. Ellis MW, Griffith ME, Dooley DP, et al. Targeted intranasal mupirocin to prevent colonization and infection by community associated methicillin resistant Staphylococcus aureus strains in soldiers: a cluster randomized controlled trial. Antimicrob Agents Chemother 2007;51(10):3591-3598.

36. Whitman TJ, Herlihy RK, Schlett CD, et al. Chlorhexidine-impregnated cloths to prevent skin and soft tissue infection in Marine recruits: a cluster-randomized, double-blind, controlled effectiveness trial. Infect Control Hosp Epidemiol 2010;31(12):1207-1215.

37. Clinical and Laboratory Standards Institute (CLSI). Performance Standards for Antimicrobial Susceptibility Testing; Twenty-Third Informational Supplement. CLSI document M100-S23. Wayne, PA: Clinical and Laboratory Standards Institute; 2013.

38. Sellick JA, Jr. The use of statistical process control charts in hospital epidemiology. Infect Control Hosp Epidemiol. 1993;14(11):649-656.

39. Boyce JM. Are the epidemiology and microbiology of methicillin-resistant Staphylococcus aureus changing? JAMA 1998;279(8):623-624.

40. Baechler MC, Williamson J, Gilbride TL, et al. Building America Best Practices Series: Guide to Determining Climate Regions by County. 2010. 
Prepared: December 2014

EpiData Center Department

41. Huang H, Flynn NM, King JH, et al. Comparisons of community-associated methicillinresistant Staphylococcus aureus (MRSA) and hospital-associated MRSA infections in Sacramento, California. J Clin Microbiol 2006;44(7):2423-2427.

42. O’Sullivan MVN, Yongwei C, Fanrong K, et al. Influence of disk separation distance on accuracy of the disk approximation test for detection of inducible clindamycin resistance in Staphylococcus spp. J Clin Microbiol 2006;44(1):4072.

43. Woods CR. Macrolide-inducible resistance to clindamycin and the D-test. Pediatr Infect Dis J 2009;28(12):1115-1118. 
MRSA Infections in the DOD: Annual Report 2013

NCMPHC-EDC-TR-44-2015

Prepared: December 2014

EpiData Center Department

\section{Acronym/Abbreviation List}

\begin{tabular}{|l|l|}
\hline Acronym/Abbreviation & Definition \\
\hline AD & Active duty \\
\hline CA & Community-associated \\
\hline CDC & Centers for Disease Control and Prevention \\
\hline CHCS & Composite Health Care System \\
\hline CL & Center Line \\
\hline CLSI & Clinical and Laboratory Standards Institute \\
\hline CY & Calendar year \\
\hline DMDC & Defense Manpower Data Center \\
\hline DOD & Department of Defense \\
\hline DON & Department of the Navy \\
\hline EDC & EpiData Center Department \\
\hline HA & Hospital-associated \\
\hline HL7 & Health Level 7 \\
\hline HO & Hospital-onset \\
\hline ICU & Intensive Care Unit \\
\hline IDSA & Infectious Disease Society of America \\
\hline IV & Intravenous \\
\hline LCL & Lower Control Limit \\
\hline M2 & MHS Data Mart \\
\hline MCRD & Marine Corps Recruit Depot \\
\hline MDR & Multi-drug resistant \\
\hline MHS & Military Health System \\
\hline MRSA & Methicillin-resistant Staphylococcus aureus \\
\hline MTF & Military Treatment Facility \\
\hline NMCPHC & Navy and Marine Corps Public Health Center \\
\hline NTC & Naval Training Center \\
\hline OCONUS & Outside of the continental United States \\
\hline OP & Outpatient \\
\hline PCR & Polymerase chain reaction \\
\hline SIDR & Standard Inpatient Data Record \\
\hline SPC & Statistical Process Control \\
\hline SSTI & Skin and soft tissue infection \\
\hline UCL & Upper Control Limit \\
\hline UD & Unit dose \\
\hline UIC & Unit Identification Code \\
\hline US & United States \\
\hline VRSA & Vancomycin-resistant Staphylococcus aureus \\
\hline & \\
\hline
\end{tabular}

